\title{
Vascular Pathways of Testosterone: Clinical Implications
}

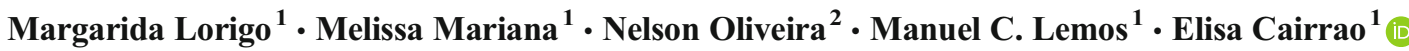

Received: 2 August 2019 / Accepted: 15 November 2019/Published online: 9 December 2019

(C) Springer Science+Business Media, LLC, part of Springer Nature 2019

\begin{abstract}
Cardiovascular diseases (CVD) are one of the leading causes of death worldwide. Testosterone (T) is an important sex hormone that triggers several genomic and non-genomic pathways, leading to improvements of several cardiovascular risk factors and quality of life in men. At the vascular level, the key effect of $\mathrm{T}$ is the vasorelaxation. This review discusses the molecular pathways and clinical implications of $\mathrm{T}$ in the vascular system. Firstly, the mechanisms involved in the $\mathrm{T}$ vasodilator effect will be presented. Then, it will be discussed the association of $\mathrm{T}$ with the main risks for CVD, namely metabolic syndrome, type 2 diabetes mellitus, obesity, atherosclerosis, dyslipidaemia and hypertension. Several studies have shown a correlation between low $\mathrm{T}$ levels and an increased prevalence of several CVD. These observations suggest that $\mathrm{T}$ has beneficial effects on the cardiovascular system and that testosterone replacement therapy may become a therapeutic reality for some of these disorders.
\end{abstract}

Keywords Androgens · Vasorelaxation · Risk factors ·

Cardiovascular diseases $\cdot$ Metabolic syndrome $\cdot$ Diabetes mellitus $\cdot$ Obesity $\cdot$ Atherosclerosis $\cdot$ Dyslipidaemia $\cdot$ Blood pressure

\section{Introduction}

The predominant endogenous androgen in the bloodstream is testosterone (T) [1]. Circulating $\mathrm{T}$ is mainly bound to serum proteins, such as sexual hormone-binding globulin (SHBG)

Associate Editor Yihua Bei oversaw the review of this article

Elisa Cairrao

ecairrao@fcsaude.ubi.pt

Margarida Lorigo

margarida.lorigo@gmail.com

Melissa Mariana

melissa.r.mariana@gmail.com

Nelson Oliveira

nelsonoliveira@ipg.pt

Manuel C. Lemos

mclemos@fcsaude.ubi.pt

1 CICS-UBI - Centro de Investigação em Ciências da Saúde, University of Beira Interior, 6200-506 Covilhã, Portugal

2 UDI-IPG - Research Unit for Inland Development, Polytechnic Institute of Guarda, Av. Dr. Francisco de Sá Carneiro, 6300-654 Guarda, Portugal and albumin [2] being the $\mathrm{T}$ concentrations higher than its solubility. Only $2-3 \%$ of all circulating $T$ is free [1], reaching its maximum in 30-year-old men, and continuously decreasing $1-2 \%$ per year afterwards [3, 4]. From the molecular point of view, T can be converted to dihydrotestosterone (DHT) by the $5 \alpha$-reductase enzyme or to oestradiol by aromatase [5]. DHT has more affinity for the androgen receptor (AR), being the most active androgen. Nevertheless, the plasma DHT concentration is much lower compared to $\mathrm{T}$ [6] since the adult male testes produce more T than DHT. However, these levels can vary with the circadian rhythm and stress. Moreover, $\mathrm{T}$ is not a male-exclusive hormone. Women produce androgens in the ovaries and adrenal glands [3, 7] and, during the pregnan$\mathrm{cy}$, the fetoplacental unit synthesizes androgens and oestrogens that play an important biological role in these development stages [8]. The chemical structure of $\mathrm{T}$ can be seen in Fig. 1.

$\mathrm{T}$ presents genomic and non-genomic actions at the vascular level, and both effects may overlap. The key $\mathrm{T}$ effect at the vascular level is the vasorelaxation, a non-genomic action (rapid effect) [9]. Over the years, several studies have agreed that $\mathrm{T}$ is an important sex hormone that triggers genomic and non-genomic pathways, leading to improvements of several cardiovascular risk factors and quality of life in men [10]. So, 


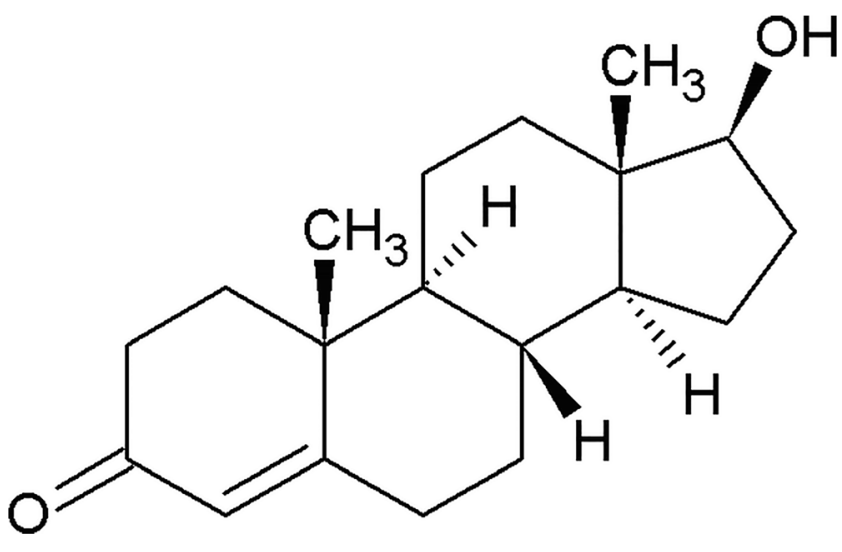

Fig. 1 Chemical structure of testosterone (T)

it is very important to understand the relationship between the risk factors for cardiovascular diseases (CVD) and T, based on the knowledge of $\mathrm{T}$ vasodilator mechanisms. Thus, in the first topic of this paper, the mechanisms involved in the $\mathrm{T}$ vasodilator effect will be briefly presented and then, in the subsequent sections, it will be discussed the association of $\mathrm{T}$ with the main risks for the CVD, namely metabolic syndrome, type 2 diabetes mellitus, obesity, atherosclerosis, dyslipidaemia, and hypertension. The final aim of this review is to clarify the clinical implications of testosterone in the vascular system.

\section{Genomic and Non-genomic Overlapping Vasodilatory Mechanisms of Testosterone}

As previous described, at the vascular level, T presents genomic and non-genomic overlapping actions that lead to an improvement of the risk factors for the CVD development/ progression [10].

The genomic effects of androgens, including those of $\mathrm{T}$, are initiated by their passage through the cellular plasma membrane into the cytoplasm. Then, they dissociate from the chaperone proteins and bind to AR, leading to alterations in specific genes. These alterations include an increase of the hydrogen sulphide $\left(\mathrm{H}_{2} \mathrm{~S}\right)$ production, and consequently vasodilation via transient receptor potential vanilloid 4 (TRPV4) and largeconductance $\mathrm{Ca}^{2+}$-activated $\mathrm{K}^{+}$channels $\left(\mathrm{BK}_{\mathrm{Ca}}\right)$ [10]. However, there are only a few studies regarding the androgen genomic effects at the cardiovascular level. In animal arteries, it has been suggested that androgens lead to an increase in the expression of calcium and potassium channels [11, 12] as well as that of soluble guanylate cyclase [13]. Moreover, an increase in the expression of voltage-dependent calcium channels in rat heart [14] and T-type calcium currents in neonatal rat heart [2] by androgens have also been reported. Regarding the human arteries, it has been shown that androgens cause another gene alteration that modifies the vascular tone, by downregulation of L-type voltage-operated $\mathrm{Ca}^{2+}$ channels
(L-type VOCC) and upregulation of $\beta 1$ subunit of $\mathrm{BK}_{\mathrm{Ca}}$ channels [15].

As previously mentioned, the main non-genomic effect of $\mathrm{T}$ on the vasculature is the vasorelaxation [9]. The major mechanisms involved in this effect include the nuclear or membrane receptor activation, influence of vascular endothelium and activation or blocking of ion channels. Concerning the activation of androgen nuclear receptors, the participation of AR in vasodilation is controversial, as some authors suggested the presence of this receptor on the cell membrane [16]. Moreover, some authors observed that the $\mathrm{T}$ vasodilatory effect was inhibited by the AR antagonist $[17,18]$. On the other hand, several authors demonstrated that the use of the AR antagonist (flutamide) [19-21], albumin-bound androgen analogues, which cannot pass through the membrane [19] and protein synthesis inhibitors [22] are not involved in T vasodilator effect. Besides, some authors also observed that $\mathrm{T}$ induced vasodilation in arteries without the nuclear functional $\operatorname{AR}[20,23,24]$, thereby demonstrating that this effect was not mediated by AR [20]. Several hypotheses have been proposed to explain the rapid androgens' vascular responses, namely a steroid nuclear receptor translocation to the cell membrane surface, nonspecific effects of steroids on plasma membrane fluidity or direct allosteric modification of ion channels dependent of binders and $\mathrm{G}$ protein-coupled receptors (GPRCs) [25]. However, concerning T, only nuclear receptor translocation to the cell membrane surface has been reported. Recently, four new membrane AR have been suggested to be responsible for the non-genomic effects of androgens. Two of them are GPCR (OXER1 and GPR6A) and the other ion channels/ transporters for calcium and zinc (TRPM8 and ZIP9) respectively [23, 24].

Regarding the vascular endothelium, the key contributor to the androgen vasorelaxation effect is controversial. Some studies demonstrated that vascular endothelium has a major role in the $\mathrm{T}$ vasodilator mechanism $[26,27]$, depending on species and gender. On the contrary, others demonstrated that this effect may occur through an independent-endothelium pathway [28-30], by direct action of T on the vascular smooth muscle. This last pathway seems to involve activation of the receptor coupled to $G_{i / o}$ protein, activating protein kinase $A$, which in turn leads to a hyperpolarization and consequently small conductance calcium-activated potassium $\left(\mathrm{SK}_{\mathrm{Ca}}\right)$ and $\mathrm{BK}_{\mathrm{Ca}}$ channels activation [31].

Concerning the effects on ion channels, several studies suggested that $\mathrm{T}$ exerts its vasodilatory effects by modulating different $\mathrm{K}^{+}$and/or $\mathrm{Ca}^{2+}$ channels [15, 21, 32-34]. The vascular tone is controlled by the ion flow, and the activation of $\mathrm{K}^{+}$channels represents the key mechanism involved in the relaxation $[35,36]$. This activation of $\mathrm{K}^{+}$channels causes a membrane hyperpolarization that closes the $\mathrm{Ca}^{2+}$ channels, leading to vasorelaxation $[37,38]$, and showing the close relationship between the channels mentioned. Most works agree 
that $\mathrm{T}$ activates the $\mathrm{K}^{+}$channels and/or inhibits the VOCC. In this case, the authors suggested that $\mathrm{T}$ can directly inhibit these channels $[30,39]$ or that this inhibition can occur indirectly by the $\mathrm{K}^{+}$channels activation, mainly the $\mathrm{K}_{\mathrm{V}}$ and $\mathrm{BK}_{\mathrm{Ca}}$ channels (due to PKG activation upon intracellular cGMP increase) [40]. Since there is no consensus regarding the exact mechanism of these $\mathrm{T}$ effects, more studies must be performed to establish if they are direct or due to the activation of a signalling pathway.

The overlap between genomic and non-genomic T actions makes it difficult to define the broad vascular effects of androgens. Increases in androgen concentrations can induce a rapid first phase effect followed by a broader, second phase; the genomic effects can modulate the effects of the first phase. To our knowledge, there are only two studies that demonstrate simultaneously both types of effects and this analysis is crucial to determine the repercussions of conceivably long-lasting therapy with androgens or a maintained increase in androgen levels. Er et al. (2007), using rat ventricular myocytes, demonstrated that the genomic $\mathrm{T}$ effects on L-type VOCC are completely antagonized by the non-genomic effects following T addition [41]. More recently, Saldanha et al. (2013) demonstrated that the genomic effects of androgens changed the expression of the $\mathrm{BK}_{\mathrm{Ca}} \beta 1$-subunit, and the $\mathrm{BK}_{\mathrm{Ca}}$ and $\mathrm{K}_{\mathrm{V}}$ channels activities change the non-genomic $\mathrm{T}$ action. These authors also suggested that androgens could be beneficial for the prevention of hypertension, once androgens have direct vasodilator effects and the increase of the $\mathrm{BK}_{\mathrm{Ca}}$ channels expression results in greater involvement of $\mathrm{K}_{\mathrm{V}}$ channels as mediators of vasodilation [15].

The vasodilator mechanism of testosterone, including the genomic and non-genomic actions, is illustrated in Fig. 2. As can be seen in the figure, both effects may overlap.

\section{Association of Testosterone with Risk Factors for CVD}

Testosterone was initially considered to be harmful to the cardiovascular system, as men have a high prevalence of CVD and cardiovascular morbidity and mortality are over 2-fold greater in men compared to women [42]. However, several clinical and epidemiological studies have challenged this idea. It was observed that men with CVD, type 2 diabetes mellitus (T2DM), obesity, metabolic syndrome (MeSy) and dyslipidaemia had low levels of $\mathrm{T}$ [43-45]. Also, the prevalence of CVD increases in ageing men, when $\mathrm{T}$ production declines. These observations suggest that this hormone has beneficial effects on the cardiovascular system and that the testosterone replacement therapy (TRT) may become a therapeutic reality for some of these pathologies. However, more recent studies have shown that TRT may be associated with an increased incidence of adverse cardiovascular events, leading to an intensified controversy regarding the cardiovascular benefits of TRT [46-48]. Thus, in this section, we will address the association of $\mathrm{T}$ with the main risk factors for CVD development, namely metabolic syndrome, type 2 diabetes mellitus, obesity, atherosclerosis, dyslipidaemia, and hypertension. An abstract illustration of the main risk factors for CVD is represented in Fig. 3.

\section{Testosterone and Metabolic Syndrome and Type 2 Diabetes Mellitus}

The MeSy is a complex combination of risk factors for CVD and diabetes. These factors include dysglycemia (i.e. elevated fasting glucose), raised blood pressure, dyslipidaemia (i.e. elevated triglyceride levels and low high-density lipoprotein (HDL) cholesterol levels) and obesity [42, 49]. The molecular mechanisms behind this complex clinical condition can be explained by the bidirectional mechanism between hypogonadism and obesity - a mechanism that involves not only adipocytes but Leydig cells and hypothalamic hormones responsible for pituitary-testicular axis control. Also, excessive leptin production (as observed in obesity) may be an ally of this mechanism, as it disrupts testicular [50]. Patients with MeSy have twice the risk of developing CVD in the next 5-10 years than individuals without MeSy and a 5-fold increased risk for developing T2DM [49]. The most popular definitions used for MeSy are [49, 51]:

WHO (World Health Organization) 1999:

Presence of insulin resistance or glucose $>6.1 \mathrm{mmol} / \mathrm{L}$ (110 mg/dL), 2 h glucose $>7.8 \mathrm{mmol}(140 \mathrm{mg} / \mathrm{dL})$ (required) along with any two or more of the following: HDL cholesterol < $0.9 \mathrm{mmol} / \mathrm{L}(35 \mathrm{mg} / \mathrm{dL})$ in men, < $1.0 \mathrm{mmol} / \mathrm{L}$ (40 mg/dL) in women

Triglycerides $>1.7 \mathrm{mmol} / \mathrm{L}(150 \mathrm{mg} / \mathrm{dL})$

Waist/hip ratio $>0.9$ (men) or $>0.85$ (women) or body mass index $(\mathrm{BMI})>30 \mathrm{~kg} / \mathrm{m}^{2}$

Blood pressure $>140 / 90 \mathrm{mmHg}$

NCEP (National Cholesterol Education Program) ATP3 2005:

Presence of any three or more of the following:

Blood glucose greater than $5.6 \mathrm{mmol} / \mathrm{L}(100 \mathrm{mg} / \mathrm{dL})$ or drug treatment for elevated blood glucose

HDL cholesterol $<1.0 \mathrm{mmol} / \mathrm{L}(40 \mathrm{mg} / \mathrm{dL})$ in men, $<1.3 \mathrm{mmol} / \mathrm{L}(50 \mathrm{mg} / \mathrm{dL})$ in women or drug treatment for low HDL-C

Blood triglycerides $>1.7 \mathrm{mmol} / \mathrm{L}(150 \mathrm{mg} / \mathrm{dL})$ or drug treatment for elevated triglycerides

Waist $>102 \mathrm{~cm}$ (men) or $>88 \mathrm{~cm}$ (women)

Blood pressure $>130 / 85 \mathrm{mmHg}$ or drug treatment for hypertension 


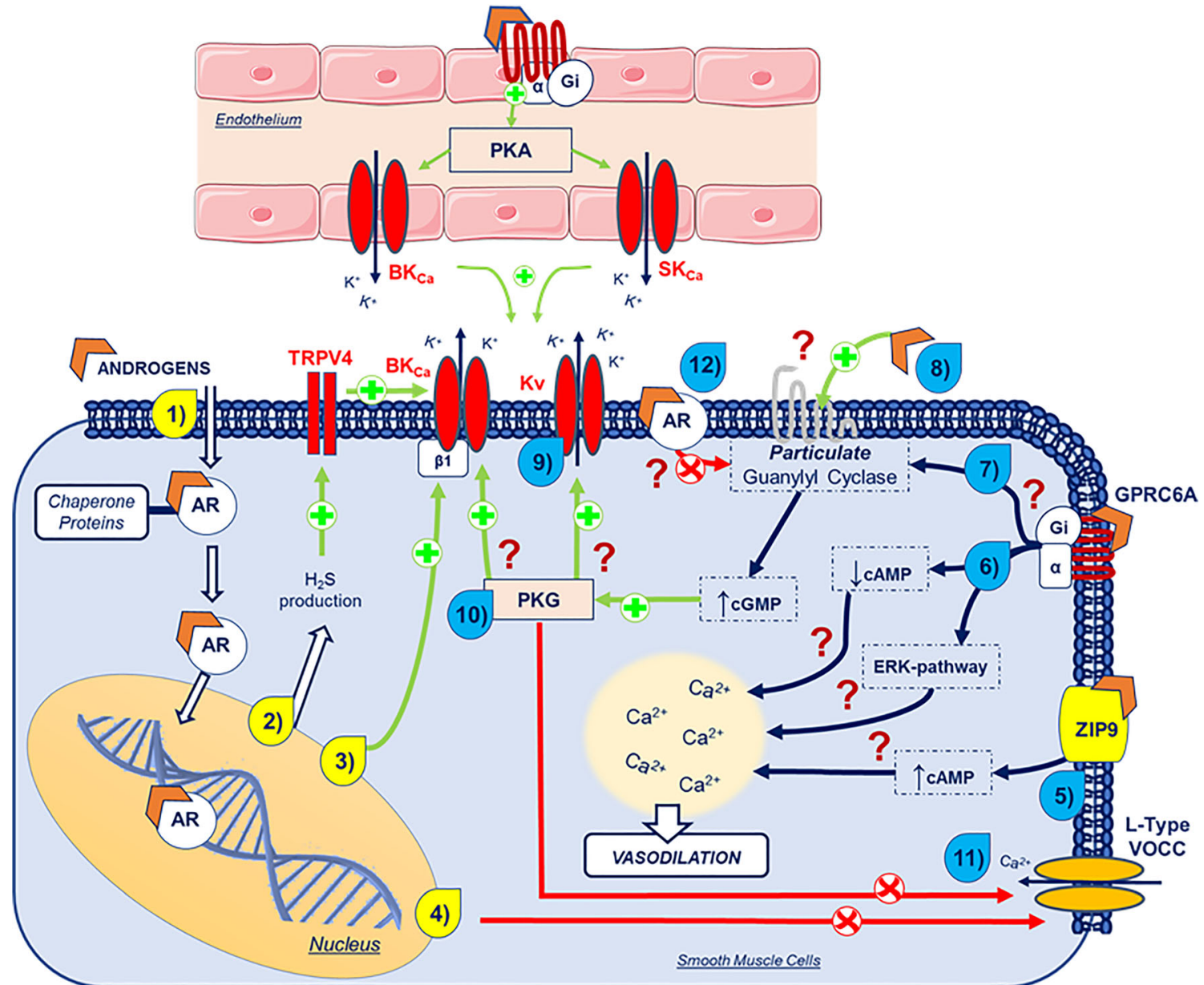

Fig. 2 Schematic representation of the overlap vasodilator genomic and non-genomic mechanisms of androgens. The yellow numbers represent the genomic actions and the blue numbers represent the non-genomic actions. (1) Androgens cross the plasma membrane and enter the cytoplasm, where it dissociates from chaperone proteins and bind to androgen receptors (AR). (2) Androgens increase the $\mathrm{H}_{2} \mathrm{~S}$ production and leads to vasodilation via TRPV4 and $\mathrm{BK}_{\mathrm{Ca}}$. (3) Androgens upregulate $\beta 1$ subunit $\mathrm{BK}_{\mathrm{Ca}}$. (4) Androgens downregulate L-type VOCC. (5) Androgens activate the ZIP9 and lead to a cAMP increase. (6) Through binding to GPRC6A ( $\mathrm{G}_{\mathrm{i}} \alpha$-activation), androgens lead to a cAMP decrease and ERK pathway activation. These two mechanisms modulate intracellular $\mathrm{Ca}^{2+}$ levels and lead to vasodilation through mechanisms still unknown. (7) Through binding to $\mathrm{G}_{\mathrm{i}} \alpha$, androgens are thought to activate particulate guanil cyclase, by a mechanism that is not yet known. (8) Androgens are thought to activate protein receptors, leading to a cGMP increase by particulate guanil cyclase activation. This increase in cGMP levels leads to $\mathrm{PKG}$ activation. Through PKG activation, androgens activate (9) $\mathrm{K}_{\mathrm{v}}$ and (10) $\mathrm{BK}_{\mathrm{Ca}}$ channels and inactivate (11) L-type VOCC channels through mechanisms still unknown. (12) Via androgen receptors (AR), it is thought that these sex hormones inhibit particulate guanil cyclase. Legend: 0 , peptide receptor; $\mathbb{P}$, androgens; 7 green arrows, stimulation; 8 red arrows, inhibition; ?, unknown mechanism; AR, androgen receptors; $\mathrm{BK}_{\mathrm{Ca}}$, large-conductance $\mathrm{Ca}^{2+}$-activated $\mathrm{K}^{+}$channels; $\mathrm{Ca}^{2+}$, calcium; cAMP, cyclic adenosine monophosphate; cGMP, cyclic guanosine monophosphate; ERK, extracellular signal-regulated kinase; GPRC6A, G protein-coupled receptor family $\mathrm{C}$ group 6-member A; $\mathrm{H}_{2} \mathrm{~S}$, hydrogen sulphide; HSP, heat shock proteins; $\mathrm{K}^{+}$, potassium; $\mathrm{K}_{v}$, voltage-gated $\mathrm{K}^{+}$channels; L-Type VOCC, L-type voltage-operated $\mathrm{Ca}^{2+}$ channels; PKG, protein kinase G; TRPV4, transient receptor potential vanilloid 4; ZIP9, Zrt- and Irt-like protein 9
IDF (International Diabetes Federation) 2006:

Waist $>94 \mathrm{~cm}$ (men) or $>80 \mathrm{~cm}$ (women) along with the presence of two or more of the following:

Blood glucose greater than $5.6 \mathrm{mmol} / \mathrm{L}(100 \mathrm{mg} / \mathrm{dL})$ or diagnosed diabetes

HDL cholesterol $<1.0 \mathrm{mmol} / \mathrm{L}(40 \mathrm{mg} / \mathrm{dL})$ in men, $<$ $1.3 \mathrm{mmol} / \mathrm{L}(50 \mathrm{mg} / \mathrm{dL})$ in women or drug treatment for low HDL-C
Blood triglycerides $>1.7 \mathrm{mmol} / \mathrm{L}(150 \mathrm{mg} / \mathrm{dL})$ or drug treatment for elevated triglycerides Blood pressure $>130 / 85 \mathrm{mmHg}$ or drug treatment for hypertension

Note: NCEP and IDF definitions are very similar except in the waist parameter of $102 \mathrm{vs} .94 \mathrm{~cm}$ in men and 88 vs. $80 \mathrm{~cm}$ in women. 
Fig. 3 Abstract illustration of the main risk factors for cardiovascular diseases (CVD)

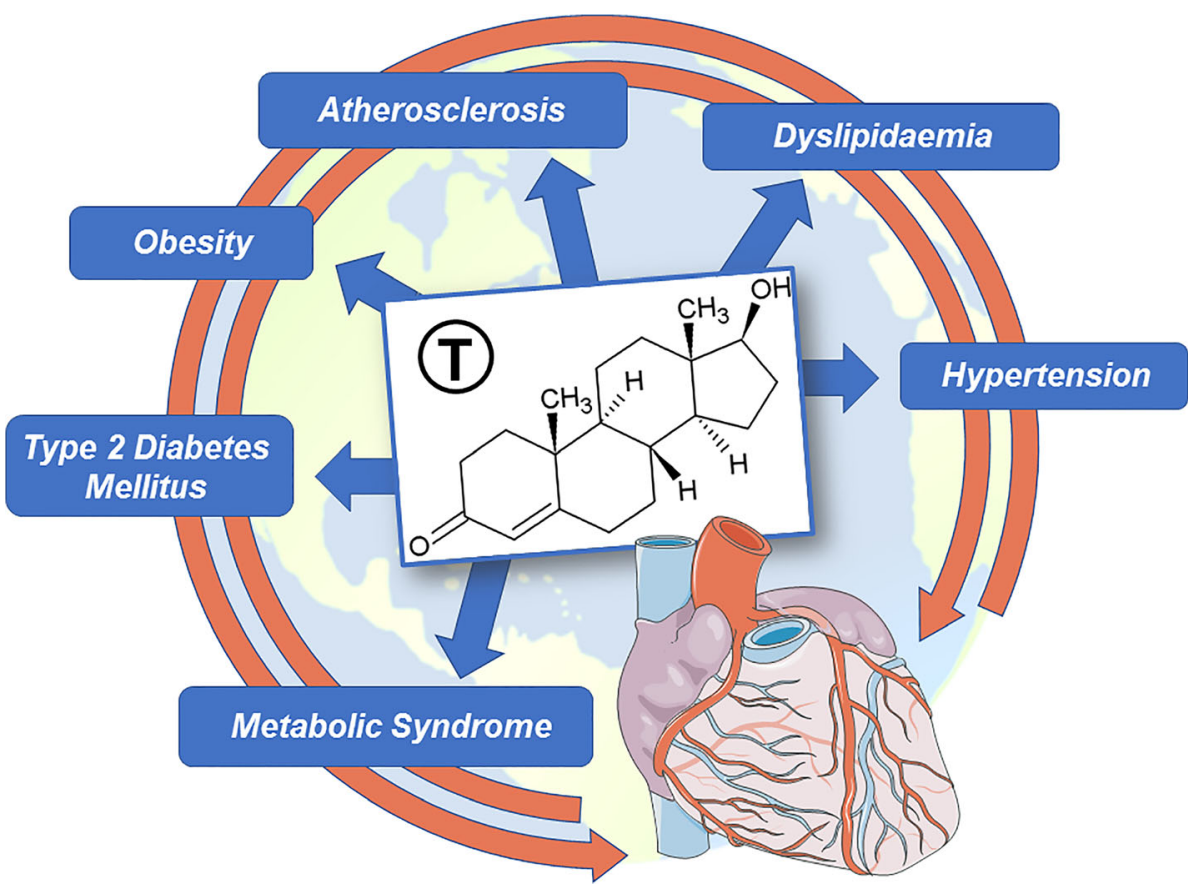

Although some studies have attempted to clarify the molecular mechanisms underlying T2DM, these remain unclear. However, most studies agree that there is insulin resistance, $\beta$ cell dysfunction, and apoptosis, as well as oxidative stress, mitochondrial dysfunction and inflammation [52].

According to the latest systematic reviews and meta-analysis, there is clear evidence that low levels of $\mathrm{T}$ are associated with an increased risk for MeSy [50, 53-56] and T2DM [54, 57, 58]. Corona et al. (2011) suggested that MeSy can be considered as an independent cause associated with male hypogonadism. Although only a few randomized controlled trials have been reported, TRT seems to be a reliable treatment to improve metabolic control, as well as central obesity [53]. It was also reported that $\mathrm{T}$ treatment has beneficial effects on all MeSy components [59]. The main criterion for the diagnosis of hypogonadism is the low blood $\mathrm{T}$ level in men, which impairs general physical and mental health status and is diagnosed in $\sim 2 \%$ of elderly men. Total and free $\mathrm{T}$ levels of less than $11 \mathrm{nmol} / \mathrm{L}$ and $0.22 \mathrm{nmol} / \mathrm{L}$, respectively, are the minimum criteria for the hypogonadism diagnosis in Europe [42, 60]. In 2013, a review performed by Corona et al. (2013) about male hypogonadism suggested that TRT was able to improve central obesity in subjects with MeSy, and glucometabolic control in patients with MeSy and T2DM. However, the authors admitted that the number of studies was too small to draw firm conclusions [54]. Regarding the two studies performed by Brand's group, a meta-analysis performed in 2011 suggested a sex-dependent association between $\mathrm{T}$ and MeSy, as the total and free $\mathrm{T}$ levels were lower in men with MeSy and higher in women with MeSy, when compared to men and women without pathologies. However, there are no indications for a sex-specific association between SHBG and MeSy, since, in both men and women, MeSy is associated with lower SHBG levels [55]. In 2014, Brand et al. suggested that low total and free $\mathrm{T}$ were associated with abdominal obesity, hypertriglyceridemia, hyperglycaemia, low HDL levels and hypertension [56]. In the same year, Cai et al. (2014) suggested that, in T2DM hypogonadal men, TRT could improve glycaemic control and decrease triglyceride levels. However, the authors of this systematic review concluded that the limited number of participants and the confounding factors must be considered when assessing the metabolic effects of TRT and its long-term influence on hypogonadal men with T2DM [61].

Another meta-analysis was performed to study the association between T and T2DM. Ding et al. (2006) showed that high $\mathrm{T}$ levels were associated with an elevated risk of developing T2DM in women and with a lower risk in men, and higher SHBG levels induced a lower risk of T2DM in women than in men [58]. Corona et al. (2011) had suggested that T2DM can be independently associated with male hypogonadism, although TRT seems to improve glucometabolic control as well as fat mass in T2DM subjects [57]. More recently, a cohort study and meta-analysis with postmenopausal women suggested that the association of SHBG with T2DM did not change with the menopause status, whereas the associations between the endogenous sex hormones and T2DM occurred only in postmenopausal women. SHBG and total oestradiol are independent risk factors for the development of T2DM in women and no association was observed between total or free $\mathrm{T}$ with T2DM [62]. 
Moreover, several studies clearly showed that TRT induced metabolic beneficial effects in MeSy and T2DM patients. The two meta-analyses performed by Corona et al. in hypogonadal MeSy patients suggested some benefits of TRT in the reduction of waist circumference, fasting glucose, and insulin resistance, and in the increase of HDL levels $[53,54]$. The reduction of fasting glucose, glycated haemoglobin (HbAlc), triglyceride and body fat were also suggested in hypogonadism and T2DM patients submitted to TRT, although total cholesterol, HDL cholesterol, blood pressure, and body mass index did not seem to be affected [54, 61]. In contrast, patients with MeSy and/or T2DM in the absence of classic hypogonadism did not show these TRT benefits regarding glycaemic control (assessed by $\mathrm{HbA1c}$ ) or constitutional symptoms reported by Ageing Male Symptom score [63].

In summary, most of the mentioned studies showed that low $\mathrm{T}$ levels are associated with an increased risk of MeSy and T2DM. Recent systematic reviews and meta-analyses showed that this beneficial effect is more important in MeSy and T2DM hypogonadal males, and the beneficial effects are not only associated with fasting glucose, glycated haemoglobin and cholesterol levels, but also with obesity, which will be explored in the next section.

\section{Testosterone and Obesity}

According to the WHO, overweight and obesity are defined as abnormal or excessive fat accumulation that presents a risk to health, in which a person with $\mathrm{BMI} \geq 25 \mathrm{~kg} / \mathrm{m}^{2}$ is generally considered overweight, while a BMI $\geq 30 \mathrm{~kg} / \mathrm{m}^{2}$ is considered obese [64]. Obesity is directly or indirectly related to metabolic disorders and the development and progression of T2DM. It leads to inflammation of adipose tissue with consequent dysglycemia and insulin resistance, alterations in the lipid metabolism and in the blood pressure, which together may lead to endothelial dysfunction and atherogenesis [65]. Because obesity has been implicated in the pathophysiology of CVD, it is important to understand the relationship between obesity and androgen deficiency, and how it contributes to the several pathophysiological states of the cardiovascular system [66].

As it is well known, obesity leads to a larger size of adipose cells (the so-called adipocyte hypertrophy) [67], which is a determinant factor to this metabolic disorder. These metabolic changes may lead to a reduction of $\mathrm{T}$. In fact, it was demonstrated that low levels of this sex hormone are associated with increased fat mass (mainly central adiposity but also visceral adiposity $[66,68,69])$, and with the reduction of lean mass, in men [70]. A bidirectional relationship between $\mathrm{T}$ and obesity supports the hypogonadism-obesity cycle [70], but it is still unclear whether obesity induces low levels of T or vice versa. It has been suggested that androgen deficiency is a consequence, and not a cause, of obesity [71]. This seems to agree with other studies that suggest that obesity promotes a faster decline of T and SHBG levels with age $[66,67,72]$, and that weight loss increases circulating $\mathrm{T}$ levels in obese men [73-75]. Even if the complete mechanism is not yet defined, these studies suggest that adipocyte hypertrophy and metabolic changes lead to decreased T levels [67].

In adipose tissue, particularly in visceral fat, $\mathrm{T}$ is converted to $17 \beta$-oestradiol by aromatase [68] which is highly expressed in adipocytes [70]. After this enzymatic conversion, oestrogens act on the hypothalamic-pituitary-gonadal (HPG)-axis to inhibit the release of hypothalamic gonadotropin-releasing hormone $(\mathrm{GnRH})$, which in turn inhibits the release of pituitary luteinizing hormone (LH) and ultimately contributes to a decrease of gonadal T [70]. Low T levels will lead to lower oestrogen levels from aromatization, reducing the activated ER and, therefore, increasing the visceral fat deposition and insulin resistance in men. Thus, $\mathrm{T}$ suppresses visceral fat deposition through its aromatization to oestradiol, which seems to be inversely related to $\mathrm{T}$ levels and to be dependent on ER $\alpha$ and aromatase [69]. An increase in visceral fat will increase adipocyte size and aromatase expression, leading to greater conversion of $\mathrm{T}$ to oestrogen, thereby lowering $\mathrm{T}$ levels. Obesity can lead to decreased levels of $\mathrm{T}$ and, in turn, low $\mathrm{T}$ levels also contribute to an increase in adiposity $[69,70]$. Furthermore, the adipose tissue is also an endocrine organ secreting several factors that will influence the pathogenesis of obesity and hypogonadism. This process is considered as the hypogonadism-obesityadipocytokine cycle [70]. In addition to oestrogens, there are inflammatory adipocytokines (e.g. tumour necrosis factor-alpha, TNF $\alpha$, and interleukin-6, IL-6) whose hypothalamic inhibitory action is the same, leading to the reduction of T levels $[70,76]$. Leptin, a hormone derived from adipose tissue that regulates body weight and food intake, and that stimulates GnRH under normal conditions, is increased with increased adiposity [77]. This may render the hypothalamus resistant to stimulation (unresponsiveness) and unable to lead to a normal $\mathrm{T}$ production [70]. Leptin interference in androgen production (via the LH-hCG pathway) [78] is another explanation for the low T levels. Accordingly, it was recently demonstrated that a high-fat diet decreases $\mathrm{T}$ levels through the suppression of testicular leptin and Janus kinase/signal transducers and activators of transcription (JAK-STAT) pathway [79]. The fact that Leydig cells have insulin receptors and are sensitive to hyperinsulinemia also indicates another direct point of interaction between the production and secretion of this hormone $[76,80]$. It seems clear that an increase in adiposity negatively affects the T secretion through multiple pathways [81], contributing progressively to CVD.

Taken together, these studies show an inverse relationship between low $\mathrm{T}$ levels and obesity, based on a bidirectional mechanism [70], where each of the two components potentiates the adverse effects of the other, increasing the risk of CVD [82]. Theoretically, when multiple changes are 
pathologically linked by bidirectional relationships, a therapeutic intervention directed at any of them may lead to an improvement of all associated conditions [83]. However, whatever the causality direction, $\mathrm{T}$ seems to be the key to this process. TRT has been shown to be effective and to improve some obesity components, i.e. decreased visceral and body fat mass, BMI and waist circumference, and increased lean mass, thus improving the body composition [69]; TRT also resulted in cardiometabolic factors improvement [70]. However, the mechanisms underlying $\mathrm{T}$ effects on obesity, or vice versa, are still not fully understood. Obesity is based on metabolic homeostasis dysregulation (involving different signalling pathways) but the way it disrupts the endocrine environment [84], or the causal relationship with T, have not yet been fully unveiled and therefore require additional investigations. The relationship between low T levels, obesity, and CVD is very complex and multifactorial, remaining, so far, poorly understood [82].

\section{Testosterone and Atherosclerosis}

Atherosclerosis is characterized by lipid accumulation and mononuclear leukocyte infiltration in the tunica intima of vessels. The molecular mechanisms that may be involved in the development and progression of atherosclerosis include the low-density lipoproteins (LDL) levels increase. Several conditions, mainly hypertension, smoking, and diabetes, have also been associated to the induction of this pathology. As it affects the cardiac circulation, it can cause myocardial infarction or stable angina pectoris. Atherosclerosis may also underlie ischaemic stroke and transient cerebral ischaemic attack, and lead to the formation of aneurysms, including in the aorta [85]. The onset and progression of arteriosclerosis can be detected by a surrogate carotid marker called intima-media thickness (IMT). This biomarker is measured by carotid ultrasonography and it is used worldwide since it is a simple, reproducible and non-invasive method [86].

Several cross-sectional and longitudinal studies have shown an inverse association between $\mathrm{T}$ levels and carotid IMT [87-92]. In a study with 403 men, aged 73-94 years, Van den Beld et al. (2003) observed that T, estrone, and insulin-like growth factor I (IGF-I) concentrations were inversely correlated with mean IMT, and this association was stronger in the group without CVD [87]. Fukui et al. (2003) enrolled 253 men with T2DM, with a mean age of 62 years, and suggested that free $\mathrm{T}$ concentrations were inversely correlated with mean IMT and plaque score. Patients with low concentrations of free $\mathrm{T}(<10 \mathrm{pg} / \mathrm{mL})$ had greater IMT and plaque score mean than those with higher concentrations of free T [88]. De Pergola et al. (2003), in a study with 127 glucose-tolerant and obese men, aged 18 to 45 years, showed that $\mathrm{T}$ levels were negatively associated with IMT, regardless of body fat and other well-known cardiovascular risk factors, suggesting that $\mathrm{T}$ may have a direct anti-atherosclerotic effect. Furthermore, the authors also observed an inverse association between $\mathrm{T}$ levels and BMI, fat mass, and waist circumference [90]. In a study of 195 men, aged 73 to 91 years, Muller et al. (2004) suggested that low free $\mathrm{T}$ levels and high oestradiol levels were inversely related to the thickening of the carotid IMT and these associations were independent of cardiovascular risk factors [91]. Makinen et al. (2005), in a study of 239 men (40-70 years), demonstrated an association between $\mathrm{T}$ levels, andropause and carotid IMT, suggesting that men with andropause symptoms, together with impaired sex hormone status and increased carotid IMT, might benefit from TRT to decelerate the progression of atherosclerosis and protect them from its clinical sequelae (i.e. coronary heart disease, ischemic stroke, and peripheral vascular disease) [92]. In 2006, Svartberg et al. (2006) suggested that total the T levels of 1482 men, aged 25-84 years, were significantly inversely related to the carotid IMT, and this association was independent of age, CVD risk factors and lifestyle factors but was not independent of BMI [89]. In a study of 354 men, aged 65 years, Soisson et al. (2012) showed that low free T combined with high C-reactive protein (CRP) levels were associated with elevated carotid IMT in elderly men, and this association with carotid IMT was not observed for SHBG nor oestradiol [93]. Farias et al. (2014), in a study of 115 male patients, aged younger than 70 years, found a negative correlation between carotid IMT and total T concentration in middle-aged men with T2DM. Men who had low T levels also had more atherosclerotic plaques, endothelial dysfunction and higher levels of high-sensitivity CRP [94]. Moreover, Lee et al. (2014), in a study with 50-year-old men with sexual dysfunction (308) observed a significant negative correlation between total T levels and the Framingham Risk Score (FRS) [95]. This is a scoring system derived from the Framingham heart study conducted in the United States and is an instrument that uses a simple past medical history and genderspecific cholesterol levels in asymptomatic patients to predict the incidence rate of CVD in the next 10 years [96, 97]. In this sense, Lee et al. (2014) suggested that a higher T level may decrease the 10-year risk of CVD, and the occurrence of atherosclerosis, coronary artery disease and coronary events [95]. In contrast to these studies, Lee et al. (2016), using a large cohort of 3164 men from 4 ethnic origins (Caucasian, African American, Hispanic American and Asian American), aged 45 to 84 years, and without known CVD, observed that lower free $\mathrm{T}$ was associated with a higher relative risk of coronary artery $\mathrm{Ca}^{2+}$ score $>0$ and lower total $\mathrm{T}$ was associated with higher $\log$ coronary artery $\mathrm{Ca}^{2+}$ score. Lower total and free $\mathrm{T}$ were associated with lower IMT [98].

In summary, high levels of $\mathrm{T}$ seem to have an antiatherosclerotic effect, although one study did not observe such a correlation. This discrepancy needs to be clarified, mainly considering some CVD risk factors such as diabetes or 
obesity, which also appear to be involved in the progression of atherosclerosis.

\section{Testosterone and Dyslipidaemia}

Dyslipidaemia is one of the main risk factors for CVD [70, 99]. The molecular mechanisms of dyslipidaemia mainly involve an imbalance of the lipid profile, characterized by low levels of HDL and high levels of LDL $[99,100]$. Additionally, dyslipidaemia may include high levels of total cholesterol, triglycerides (TG) and very low-density lipoprotein (VLDL) [70], as well as reduced activity of lipoprotein lipase, a protein associated with increased risk of coronary artery disease (CAD) [100].

As previously mentioned, $\mathrm{T}$ can lead to dyslipidaemia, contributing to the development of CVD. Specifically, low T levels are an integral part of the MeSy, characterized not only by dyslipidaemia, but also by obesity, diabetes and hypertension [101]. Haffner et al. (1993) showed that there is a correlation between low levels of $\mathrm{T}$ and high levels of LDL, total cholesterol and TG, and low levels of HDL [102]. Moreover, Agledahl et al. (2008) inversely associated the total T with TG, and positively with HDL [103]. Following these authors, Makinen et al. (2008) correlated T directly with HDL and inversely with total cholesterol and TG [104]. Other authors, in addition to the positive association of T with HDL [105], also found an inverse relationship with VLDL levels [105, 106]. TRT was associated with beneficial decreases in LDL, total cholesterol and TG [70, 107]. Increases in HDL levels have also been reported after TRT, although there are contradictory studies where a decrease $[108,109]$ or no change [110] occurred. An explanation for these differences has not yet been found, but it is assumed that the T stimulation of reverse cholesterol transport may lead to increased HDL-C consumption [70].

Overall, individuals with low $\mathrm{T}$ levels seem to have a proatherogenic lipoprotein pattern, and thus, a higher propensity to develop MeSy and CVD. Although multiple factors contribute to atherosclerosis, dyslipidaemia has been considered as the main cause of this disease [111], with T playing a key role. In this sense, TRT induces a more favourable lipid profile, contributing to a decrease in CVD occurrence. In summary, androgens seem to provide a protective effect against the development and/or progression of atherosclerosis [111, 112].

\section{Testosterone and Blood Pressure}

Physiologically, blood pressure can be defined by Ohm's law, as being proportional to cardiac output and vascular resistance to blood flow. However, several other factors, in an integrated manner, characterize the molecular mechanism of this risk factor. Specifically, the baroreceptors detect acute pressure changes in vessels; natriuretic peptides are increased due to higher pressure on the heart; the renin-angiotensinaldosterone system influences vascular tone homeostasis; the adrenergic system influences heart rate, contraction and vascular tone; and other local mediators, such as nitric oxide and endothelin, that cause relaxation or vascular contraction, respectively. Taken together, all these factors make blood pressure changes a complex mechanism [113].

Regarding the association between $\mathrm{T}$ and blood pressure, Zitzmann and Nieschlag, in 2007, demonstrated beneficial effects of $\mathrm{T}$ in the diastolic and systolic blood pressure as well as resting heart rate, which decreased significantly during treatment with $\mathrm{T}$ in hypogonadal men $[114,115]$. Later, other authors studied the association between the increase or deficiency of androgens with gestational hypertension and preeclampsia. A positive correlation between the increase of androgen levels and preeclampsia was observed [116-118]. It was also demonstrated that the placental aromatase enzyme, that is responsible for the conversion of androgens to oestrogen, is deficient in placental ischemia and preeclamptic pregnancy $[8,119]$. On the other hand, other epidemiological studies have shown that maternal serum levels of androgens, such as dehydroepiandrosterone (DHEA), DHEA sulphate, androstenedione, and $\mathrm{T}$, are elevated in healthy pregnant women $[120,121]$. In accordance, other studies have shown that $\mathrm{T}$ and its 5 -reduced metabolites ( $5 \alpha$ - and $5 \beta$-DHT) produced a marked reduction in the blood pressure of hypertensive and normotensive rats [122]. Particularly, $5 \beta$-DHT led to a substantial acute antihypertensive effect in hypertensive rats [123], which may be mainly due to a blockade of $\mathrm{Ca}^{2+}$ entry through L-type VOCC [124]. Concerning the hypertensive disorders of pregnancy, Perusquia et al. (2018) demonstrated, for the first time in a rat model of preeclampsia, that androgens, mainly DHEA and $5 \beta$-DHT, attenuate hypertension in vivo due to their vasorelaxant effect, and this is a nongenomic mediated response [125]. In conclusion, an excess or insufficient androgen production during pregnancy may trigger the development of preeclampsia or gestational hypertension. Thus, these studies point out that the administration of androgens in women with hypertensive disorders of pregnancy is a near possibility. Nevertheless, further clinical studies are needed.

\section{Testosterone and Heart Diseases}

As described above, low levels of $\mathrm{T}$ appear to be harmful to the cardiovascular system due to the observed increase of CVD risk factors $[45,126]$. T not only influences vascular reactivity but affects peripheral resistance, cardiac electrophysiology and cardiac output [126]. It is not clear how $\mathrm{T}$ influences ventricular repolarization mechanisms, but it appears to act by activating $\mathrm{K}^{+}$channels and simultaneously reducing the activity of L-type $\mathrm{Ca}^{2+}$ channels, thereby 
increasing the repolarization reserve [69]. Decreased T is also associated with heart diseases such as coronary artery disease (CAD), heart failure (HF), ischaemic stroke, and atrial fibrillation (AF) [127].

Regarding CAD, some studies have shown an inverse association between T levels and CAD. Phillips et al. (1983) were the first authors to demonstrate that exists an inverse relationship between free $\mathrm{T}$ levels and CAD degree [128]. Similar results were later obtained by Zhao et al. (1998) [129]. In 2000, English et al. (2000) demonstrated that men have lower levels of $\mathrm{T}$ than men with normal coronary angiograms. Interestingly, the authors also found low levels of $17 ß-$ estradiol, which is suggestive of a direct action of $\mathrm{T}$ on the CAD pathogenesis [43]. Several investigations also evaluated the carotid artery by ultrasonography and demonstrated that low T levels were associated with carotid IMT [89, 93, 130, 131], total carotid plaque area [132], and intermittent claudication [133]. Rosano et al. (2007) in their investigations also demonstrated that low $\mathrm{T}$ levels and $17 \beta$-estradiol are associated with coronary artery disease in male patients with angina. These results also show that there is an inverse relationship between the degree of CAD and plasma $\mathrm{T}$ levels suggesting that low plasma $\mathrm{T}$ may be involved with the increased risk of CAD in men [134]. The clinical relevance of low oestradiol levels after normalization of $\mathrm{T}$ levels needs further investigation as both sex hormones are tightly linked.

Concerning HF, this heart disease is usually associated with an increase in peripheral vasoconstriction [126]. The most common cause of HF and impaired left ventricular dysfunction is coronary artery disease (CAD) with resulting cardiac ischemia, leading to decreased contractility and weakness of the heart muscle. It is common for men with HF to have low T levels and this leads to increased mortality [135] as they are associated with reduced heart function, loss of lean muscle mass and strength, chronic anaemia and insulin resistance [126]. Some studies have suggested that there also appears to be an inverse relationship between total and T-free levels and HF grade [69], in which case the prevalence of hypogonadism is greater than $40 \%$ [136]. It has been speculated that low $\mathrm{T}$ levels may be linked to an anabolic/catabolic imbalance, a typical feature of advanced HF. Some research supports this hypothesis as they report that low $\mathrm{T}$ levels are associated with some clinical features of advanced HF (e.g. reduction of muscle mass, decreased exercise capacity, energy handling, fatigue dyspnoea, and final cachexia) [136]. Patients with HF have decreased exercise capacity and muscle fatigue, but this is not necessarily related to the myocardial dysfunction degree [136], a fact that is supported by other investigations [137, 138]. Studies by Jankowska et al. (2006) demonstrated that low $\mathrm{T}$ levels independently predisposed to impaired exercise capacity, whereas other indices related to the heart disease progression were not [137]. Moreover, SrinivasShankar et al. (2010) also reported that age-related decline in
$\mathrm{T}$ contributes to a gradually impaired exercise capacity in older men, and $\mathrm{T}$ treatment for 6 months has been shown to prevent age-associated loss of lower limb muscle strength and improve body composition, quality of life, and physical function [138].

Some authors also tried to understand the role of $\mathrm{T}$ on stroke or myocardial infarction. Total production of $\mathrm{T}$ and free $\mathrm{T}$ levels appears to be significantly inversely associated with a higher incidence or severity of a stroke or transient ischemic attack (TIA), to the 6month mortality and the infarct size [127, 139]. Differences between patients and control subjects in serum $17 \beta$-estradiol levels were not found suggesting that $\mathrm{T}$ may directly affect the ischemic stroke pathogenesis in men [139]. Mäkinen et al. (2005) also observed that there is a positive correlation between testosterone deficiency and increased carotid IMT. Thus, these authors also suggested a possible protective role of $\mathrm{T}$ for the development of atherosclerosis in middle-aged men [92]. In the same sense, Yeap et al. (2009) also evidenced that, in older men, lower $\mathrm{T}$ levels predict incident stroke and TIA, after adjusting for conventional risk factors for CVD [140]. This can have as several consequences, such as an increase in carotid IMT, the formation of an abdominal aortic aneurysm or even the appearance of lone atrial fibrillation (AF), as demonstrated later by the same authors [141]. Older men with abdominal aortic aneurysm have reduced low free $\mathrm{T}$ levels, suggesting that an impaired gonadal function may be also involved in arterial dilatation as well as occlusive vascular disease in older men [141].

Recent evidence confirms that low $\mathrm{T}$ levels are a risk factor not only for ischemic stroke but also for AF [142, 143]. An independent association between lone AF and low levels of $\mathrm{T}$ was reported [144], suggesting that $\mathrm{T}$ may be protective for the regulation of myocardial electrical conduction. In the same sense, Zhang et al.(2017) demonstrated, in castrated mice, that $\mathrm{T}$ deficiency is responsible for the late $\mathrm{Na}^{+}$current increase, which prologues the action potential repolarization and consequently, promote an increased susceptibility to AF [145]. Even if most studies point to an association of low $\mathrm{T}$ levels with an increased risk of developing AF, it has been also shown that low levels of oestradiol [142] and DHT [146] may increase the risk of incident AF. Moreover, some studies have shown that elevated $\mathrm{T}$ levels may also be predictive of AF [147, 148]. More studies are necessary to understand these contradictory data.

Taken together, these studies demonstrated that $\mathrm{T}$ seems to be protective for the development of heart diseases suggesting, therefore, that low levels of this sex hormone are a good marker for heart disease's diagnosis. 


\section{Potential Therapeutic Application of Testosterone}

TRT may be a therapeutic reality for some of these cardiovascular events [149]. However, currently, T administration has only been approved by the Food and Drug Administration (FDA) as replacement therapy in men with low testosterone levels and with symptoms of hypogonadism, primary (testicular) or secondary (pituitary-hypothalamic). These symptoms include decreased spontaneous erections, decreased nocturnal penile tumescence decreased libido, decreased beard growth and shrinking testicles [150]. On the other hand, recent findings have shown that TRT may increase the incidence of adverse cardiovascular events, although this issue is still very controversial [46-48].

As previously described, the prescription of TRT to correct low $\mathrm{T}$ levels were associated with a decrease in the incidence of CVD risk factors [45]. A reduction in the mortality rate of men with T2DM and hypogonadism was also demonstrated. As reported in the previous topics, TRT improves fasting blood glucose, glycated haemoglobin, cholesterol levels, and obesity in men with hypogonadism [61]. Moreover, they have shown that TRT improves central obesity and metabolic control, as well as fat mass in these patients, reduced waist circumference, insulin resistance, BMI and increased HDL levels $[53,54,69]$. Other authors have also suggested that TRT may improve glycaemic control and decrease T2DM triglyceride levels in men with hypogonadism [61]. However, the mechanism behind the T/obesity/CVD relationship is very complex and to date little is known [82]. TRT also decelerates the progression of atherosclerosis and protects from its clinical sequelae [92], inducing a more favourable the lipid profile [111, 112]. Interestingly, recent studies found that TRT increases the volume of uncalcified coronary artery plaque [151, 152], although it was not associated with more $\mathrm{CV}$ adverse effects in the same investigation. The authors reported that further studies are needed to prove whether $\mathrm{T}$ increases $\mathrm{CV}$ risk. Overall, these studies seem to suggest that normal $\mathrm{T}$ levels are an anti-atherosclerotic pattern. Regarding dyslipidaemia - the main cause of atherosclerosis - some studies have also shown the role of $\mathrm{T}$ in this disorder. TRT appears to improve lipid profile, contributing to a decrease in this CVD risk factor, having, therefore, a protective role on atherosclerosis $[111,112]$. TRT has recently been shown to decrease cholesterol and insulin levels but was not associated with markers of glucose and inflammation, fibrinolysis or troponin. However, the authors noted that the clinical importance of their study was unclear and further clinical studies should be performed [153]. Concerning the blood pressure changes, some studies in men with hypogonadism have also shown that $\mathrm{T}$ has beneficial effects on diastolic and systolic blood pressure as well as resting heart rate $[114,115]$. Concerning the hypertensive disorders during pregnancy, it appears that $\mathrm{T}$ plays an important role in the pathogenesis of preeclampsia, [154]. An excess or insufficient androgen production during pregnancy may trigger the development of preeclampsia or gestational hypertension [125]. Thus, the scientific community believes that the administration of androgens in hypertensive disorders of pregnancy is a possibility, however, more clinical studies are needed.

Concerning the therapeutic application of TRT in men with symptoms of hypogonadism, several authors also tried to understand the association between hypogonadism with CVD, particularly heart failure (HF), angina or myocardial ischemia/ reperfusion [155]. Baillargeon et al. (2014) demonstrated that TRT did not increase the risk of myocardial infarction compared with a group without TRT [156]. Other authors have also observed that low $\mathrm{T}$ levels are associated with coronary heart disease [129], and men with proven coronary atherosclerosis had low endogenous androgen levels [157]. Low and high plasma levels of this hormone have also been associated with ischemic arterial disease in elderly men [158]. Moreover, Muraleedharan et al. (2013) suggested that low T levels may predict increased all-cause mortality [159].

Concerning HF, TRT appears to increase the peak oxygen consumption $\left(\mathrm{VO}_{2}\right)$ on exercise testing [160], whereas intravenous $\mathrm{T}$ administration can increase cardiac output and reduce peripheral vascular resistance [161]. The long-term (chronic) treatment has also been shown to improve some immunological parameters (TNF- $\alpha$ and IL- $1 \beta$ ) which may lead to a reduction in left ventricular muscle fibrosis [162].

Regarding ischemia/myocardial reperfusion, $\mathrm{T}$ has been shown to relax coronary arteries $[126,135,163]$ and the long-term treatment may increase the time to develop new ischemia. Clinical trials suggest that $\mathrm{T}$ has short- and longterm effects on cardiac ischemia, responsible for its nongenomic and genomic actions, respectively [44, 126, 164]. It has been suggested that coronary arteries are more sensitive to $\mathrm{T}$ in men with a higher deficiency of this hormone $[126,165]$. The molecular mechanisms underlying this situation can be explained based on the non-genomic actions of $\mathrm{T}[44,126$, 164], however, they remain unknown [135] and further studies are needed to clarify them [135].

With respect to stroke or myocardial infarction, two large observational studies reported that TRT increased the risk of these pathologies in men over 75 years $[166,167]$. Vigen et al. (2013) performed a retrospective national cohort study of men with low $\mathrm{T}$ levels who underwent coronary angiography. The obtained results demonstrated that the use of TRT was associated with an increased risk of adverse outcomes (myocardial infarction or stroke) [166]. Finkle et al. (2014) performed a cohort study in men with a higher risk of acute non-fatal myocardial infarction. The authors found TRT substantially increased the risk of myocardial infarction in older and younger men [167]. However, these two studies have been criticized once the levels of $\mathrm{T}$ and the drug administration following $\mathrm{T}$ 
treatment have not been in consideration in these studies, which may antagonize the T effects $[168,169]$. On the other hand, other authors reported a protective role of $\mathrm{T}$ in stroke or myocardial infarction $[170,171]$. The mechanisms involved in this role of T may be associated with the direct effects of this hormone on myocardial oxygen consumption and membrane repolarization [41, 135, 165]. Moreover, some studies suggested that $\mathrm{T}$ can reduce the size of myocardial infarct, but this is not consensual. Further studies are needed to unravel the role of $\mathrm{T}$ in anti-ischemic and/or antianginal therapy [135, $155]$.

In summary, these studies suggest that $\mathrm{T}$ plays an important role in human health, although it is unclear whether its actions are clinically relevant in terms of protection from CVD or in the improvement of an established disease [48, 126, 172]. Because there is no scientific evidence to support the correlation of TRT with CVD risk factors increase [47] since most of these studies report a beneficial role from this therapy, $\mathrm{T}$ administration remains a reality [45]. Despite this, the FDA has already made a warning statement about the possible CVD risk factors associated with TRT.

\section{Conclusions and Future Directions}

Cardiovascular diseases (CVD) are one of the leading causes of death worldwide. The knowledge about the vascular effects of testosterone $(\mathrm{T})$ is crucial to understand its clinical implications and may lead to new therapeutic targets in the future. Studies performed over the years agree that $\mathrm{T}$ is an important sex hormone that triggers several genomic and non-genomic pathways, leading to improvements of several cardiovascular risk factors and quality of life in men, contrary to what had been suggested at first instance. T presents genomic and nongenomic actions at the vascular level, and both effects may overlap, which makes it difficult to define the broad vascular effects of androgens. However, the key T effect at the vascular level is the vasorelaxation, a non-genomic action (rapid effect).

Several studies have established a relationship between the low levels of $\mathrm{T}$ and an increase in the CVD prevalence, which seems to be mainly linked to the nongenomic actions of $\mathrm{T}$, namely vasorelaxation. This effect involves several mechanisms including the nuclear receptor activation, the influence of vascular endothelium and the activation or blocking of ion channels. So, the vasodilator mechanisms of $\mathrm{T}$ are crucial to understanding the relationship between the risk factors for CVD and this sex hormone.

Several clinical and epidemiological studies observed that men with type 2 diabetes mellitus, obesity, metabolic syndrome, atherosclerosis, dyslipidaemia, and higher blood pressure had lower levels of $\mathrm{T}$, suggesting a beneficial role of $\mathrm{T}$ on the cardiovascular system. Therefore, testosterone replacement therapy (TRT) could be a solution to improve these CVD risk factors. However, this issue has been the subject of controversy, as recent studies suggest that TRT is associated with an increase of CVD. Concerning type 2 diabetes mellitus and metabolic syndrome, most of the studies showed an association with low levels of T and that TRT improves these risk factors in men with hypogonadism. Regarding atherosclerosis and dyslipidaemia, low levels of $\mathrm{T}$ were also associated with an improvement of some parameters of these risk factors. Moreover, TRT seems to induce a more favourable lipid profile, contributing to increased protection for the development or progression of atherosclerosis. Regarding the association between $\mathrm{T}$ and blood pressure, few studies have been performed, but it seems that $\mathrm{T}$ is beneficial to diastolic and systolic blood pressure as well as the resting heart rate. Furthermore, excess or insufficient androgen production during pregnancy may trigger the development of preeclampsia or gestational hypertension. These studies also indicate that the administration of androgens in hypertensive pregnant women is a near possibility. Nevertheless, further clinical studies are needed.

In sum, the vascular effects of testosterone have clinical implications. However, a consensus on the T effects or the risks associated with TRT on the cardiovascular system needs to be established. Considering the overlap between both genomic and non-genomic effects, and even a possible divergence in the effects of both actions, it is evidenced that a better understanding of the vascular mechanisms of testosterone is crucial. Only then their clinical implications will be correctly established and the development of new therapeutic targets for cardiovascular diseases can be discovered.

Authors' Contributions E.C. identified the need for this review; M.L., M.C.L and E.C designed the manuscript; M.L., M.M and O.L wrote the manuscript; M.L., M.M, O.L, M.C.L and E.C. reviewed the literature and E.C. and M.C.L. critically reviewed the manuscript. All authors read and approved the final manuscript.

Funding Information Margarida Lorigo acknowledges the doctoral incentive grant (BID) financed by the multiannual program contract of patronage UBI-Santander Totta (BID/FCS/2018). This work was also supported by FEDER funds through the POCI-COMPETE 2020 Operational Programme Competitiveness and Internationalisation in Axis I-Strengthening Research, Technological Development and Innovation (Project POCI-01-0145-FEDER007491) and National Funds by FCT-Foundation for Science and Technology (Project UID/Multi/ 00709/2019).

\section{Compliance with Ethical Standards}

Conflict of Interest The authors declare that they have no conflict of interest.

Ethical Approval This article does not contain any studies with human participants or animals performed by any of the authors. 


\section{References}

1. Kaushik, M., Sontineni, S. P., \& Hunter, C. (2010). Cardiovascular disease and androgens: A review. International Journal of Cardiology, 142(1), 8-14. https://doi.org/10.1016/j. ijcard.2009.10.033.

2. Michels, G., Er, F., Eicks, M., Herzig, S., \& Hoppe, U. C. (2006). Long-term and immediate effect of testosterone on single T-type calcium channel in neonatal rat cardiomyocytes. Endocrinology, 147(11), 5160-5169. https://doi.org/10.1210/en.2006-0186.

3. Elagizi, A., Kohler, T. S., \& Lavie, C. J. (2018). Testosterone and cardiovascular health. Mayo Clinic Proceedings, 93(1), 83-100. https://doi.org/10.1016/j.mayocp.2017.11.006.

4. Yeap, B. B., Page, S. T., \& Grossmann, M. (2018). Testosterone treatment in older men: Clinical implications and unresolved questions from the testosterone trials. The Lancet Diabetes and Endocrinology, 6(8), 659-672. https://doi.org/10.1016/S22138587(17)30416-3.

5. Ruehlmann, D. O., \& Mann, G. E. (2000). Rapid non-genomic vasodilator actions of oestrogens and sex steroids. Current Medicinal Chemistry, 7(5), 533-541. https://doi.org/10.2174/ 0929867003375038.

6. Longcope, C., Kato, T., \& Horton, R. (1969). Conversion of blood androgens to estrogens in normal adult men and women. The Journal of Clinical Investigation, 48(12), 2191-2201. https://doi. org/10.1172/JCI106185.

7. Rainey, W. E., \& Nakamura, Y. (2008). Regulation of the adrenal androgen biosynthesis. The Journal of Steroid Biochemistry and Molecular Biology, 108(3-5), 281-286. https://doi.org/10.1016/j. jsbmb.2007.09.015.

8. Hakim, C., Padmanabhan, V., \& Vyas, A. K. (2017). Gestational hyperandrogenism in developmental programming. Endocrinology, 158(2), 199-212. https://doi.org/10.1210/en. 2016-1801.

9. Yildiz, O., \& Seyrek, M. (2007). Vasodilating mechanisms of testosterone. Experimental and Clinical Endocrinology \& Diabetes, 115(1), 1-6. https://doi.org/10.1055/s-2007-949657.

10. Lucas-Herald, A. K., Alves-Lopes, R., Montezano, A. C., Ahmed, S. F., \& Touyz, R. M. (2017). Genomic and non-genomic effects of androgens in the cardiovascular system: Clinical implications. Clinical Science (London, England), 131(13), 1405-1418. https:// doi.org/10.1042/CS20170090.

11. Bowles, D. K., Maddali, K. K., Ganjam, V. K., Rubin, L. J., Tharp, D. L., Turk, J. R., et al. (2004). Endogenous testosterone increases L-type $\mathrm{Ca}^{2+}$ channel expression in porcine coronary smooth muscle. American Journal of Physiology. Heart and Circulatory Physiology, 287(5), H2091-H2098. https://doi.org/10.1152/ ajpheart.00258.2004.

12. Zhou, P., Fu, L., Pan, Z., Ma, D., Zhang, Y., Qu, F., et al. (2008). Testosterone deprivation by castration impairs expression of voltage-dependent potassium channels in rat aorta. European Journal of Pharmacology, 593(1-3), 87-91. https://doi.org/10. 1016/j.ejphar.2008.07.014.

13. Oka, M., Karoor, V., Homma, N., Nagaoka, T., Sakao, E., Golembeski, S. M., et al. (2007). Dehydroepiandrosterone upregulates soluble guanylate cyclase and inhibits hypoxic pulmonary hypertension. Cardiovascular Research, 74(3), 377-387. https://doi.org/10.1016/j.cardiores.2007.01.021.

14. Er, F., Gassanov, N., Brandt, M. C., Madershahian, N., \& Hoppe, U. C. (2009). Impact of dihydrotestosterone on L-type calcium channels in human ventricular cardiomyocytes. Endocrine Research, 34(3), 59-67. https://doi.org/10.1080/ 07435800903136953.

15. Saldanha, P. A., Cairrao, E., Maia, C. J., \& Verde, I. (2013). Longand short-term effects of androgens in human umbilical artery smooth muscle. Clinical and Experimental Pharmacology and Physiology, 40, 181-189. https://doi.org/10.1111/1440-1681. 12047.

16. Yu, J., Akishita, M., Eto, M., Koizumi, H., Hashimoto, R., Ogawa, S., et al. (2012). Src kinase-mediates androgen receptor-dependent non-genomic activation of signaling cascade leading to endothelial nitric oxide synthase. Biochemical and Biophysical Research Communications, 424(3), 538-543. https://doi.org/10.1016/j. bbrc.2012.06.151.

17. Steinsapir, J., Socci, R., \& Reinach, P. (1991). Effects of androgen on intracellular calcium of $\mathrm{LNCaP}$ cells. Biochemical and Biophysical Research Communications, 179(1), 90-96. https:// doi.org/10.1016/0006-291x(91)91338-d.

18. Murphy, J. G., \& Khalil, R. A. (1999). Decreased $\left[\mathrm{Ca}^{2+}\right]_{\mathrm{i}}$ during inhibition of coronary smooth muscle contraction by 17 beta-estradiol, progesterone, and testosterone. The Journal of Pharmacology and Experimental Therapeutics, 291(1), 44-52.

19. Ding, A. Q., \& Stallone, J. N. (2001). Testosterone-induced relaxation of rat aorta is androgen structure specific and involves $\mathrm{K}^{+}$ channel activation. Journal of Applied Physiology, 91(6), 27422750. https://doi.org/10.1152/jappl.2001.91.6.2742.

20. Jones, R. D., English, K. M., Pugh, P. J., Morice, A. H., Jones, T. H., \& Channer, K. S. (2002). Pulmonary vasodilatory action of testosterone: Evidence of a calcium antagonistic action. Journal of Cardiovascular Pharmacology, 39(6), 814-823. https://doi.org/ 10.1097/00005344-200206000-00006.

21. Cairrao, E., Alvarez, E., Santos-Silva, A. J., \& Verde, I. (2008). Potassium channels are involved in testosterone-induced vasorelaxation of human umbilical artery. Naunyn-Schmiedeberg's Archives of Pharmacology, 376(5), 375-383. https://doi.org/10. 1007/s00210-007-0213-3.

22. Teoh, H., Quan, A., Leung, S. W., \& Man, R. Y. (2000). Differential effects of 17 beta-estradiol and testosterone on the contractile responses of porcine coronary arteries. British Journal of Pharmacology, 129(7), 1301-1308. https://doi.org/ 10.1038/sj.bjp.0703164.

23. Thomas, P., Converse, A., \& Berg, H. A. (2018). ZIP9, a novel membrane androgen receptor and zinc transporter protein. General and Comparative Endocrinology, 257, 130-136. https:// doi.org/10.1016/j.ygcen.2017.04.016.

24. Thomas, P. (2019). Membrane androgen receptors unrelated to nuclear steroid receptors. Endocrinology, 160(4), 772-781. https://doi.org/10.1210/en.2018-00987.

25. Wang, C., Liu, Y., \& Cao, J. M. (2014). G protein-coupled receptors: Extranuclear mediators for the non-genomic actions of steroids. International Journal of Molecular Sciences, 15(9), 15412 15425. https://doi.org/10.3390/ijms150915412.

26. Hotta, Y., Kataoka, T., \& Kimura, K. (2019). Testosterone deficiency and endothelial dysfunction: Nitric oxide, asymmetric dimethylarginine, and endothelial progenitor cells. Sexual Medicine Reviews. https://doi.org/10.1016/j.sxmr.2019.02.005.

27. Higashi, Y. (2017). Lower urinary tract symptoms/benign prostatic hypertrophy and vascular function: Role of the nitric oxidephosphodiesterase type 5-cyclic guanosine 3',5'-monophosphate pathway. International Journal of Urology, 24(6), 412-424. https://doi.org/10.1111/iju.13336.

28. Crews, J. K., \& Khalil, R. A. (1999). Antagonistic effects of 17 bestradiol, progesterone, and testosterone on $\mathrm{Ca}^{2+}$ entry mechanisms of coronary vasoconstriction. Arteriosclerosis, Thrombosis, and Vascular Biology, 19(4), 1034-1040. https:// doi.org/10.1161/01.ATV.19.4.1034.

29. Deenadayalu, V. P., White, R. E., Stallone, J. N., Gao, X., \& Garcia, A. J. (2001). Testosterone relaxes coronary arteries by opening the large-conductance, calcium-activated potassium channel. The American Journal of Physiology, 281(4), H1720 H1727. https://doi.org/10.1152/ajpheart.2001.281.4.H1720. 
30. Perusquia, M., Hernandez, R., Morales, M. A., Campos, M. G., \& Villalon, C. M. (1996). Role of endothelium in the vasodilating effect of progestins and androgens on the rat thoracic aorta. General Pharmacology, 27(1), 181-185. https://doi.org/10.1016/ 0306-3623(95)00091-7.

31. Ruamyod, K., Watanapa, W. B., \& Shayakul, C. (2017). Testosterone rapidly increases $\mathrm{Ca}(2+)$-activated $\mathrm{K}(+)$ currents causing hyperpolarization in human coronary artery endothelial cells. The Journal of Steroid Biochemistry and Molecular Biology, 168, 118-126. https://doi.org/10.1016/j.jsbmb.2017.02.014.

32. Perusquia, M., Navarrete, E., Gonzalez, L., \& Villalon, C. M. (2007). The modulatory role of androgens and progestins in the induction of vasorelaxation in human umbilical artery. Life Sciences, 81(12), 993-1002. https://doi.org/10.1016/j.lfs.2007.07. 024 .

33. Yildiz, O., Seyrek, M., Un, I., Gul, H., Candemir, G., \& Yildirim, V. (2005). The relationship between risk factors and testosteroneinduced relaxations in human internal mammary artery. Journal of Cardiovascular Pharmacology, 45(1), 4-7. https://doi.org/10. 1097/00005344-200501000-00002.

34. Sakamoto, K., \& Kurokawa, J. (2019). Involvement of sex hormonal regulation of $\mathrm{K}(+)$ channels in electrophysiological and contractile functions of muscle tissues. Journal of Pharmacological Sciences, 139(4), 259-265. https://doi.org/10.1016/j.jphs.2019.02. 009.

35. Martin de Llano, J. J., Fuertes, G., Garcia-Vicent, C., Torro, I., Fayos, J. L., \& Lurbe, E. (2007). Procedure to consistently obtain endothelial and smooth muscle cell cultures from umbilical cord vessels. Translational Research, 149(1), 1-9. https://doi.org/10. 1016/j.trsl.2006.07.010.

36. Lorigo, M., Mariana, M., Feiteiro, J., \& Cairrao, E. (2018). How is the human umbilical artery regulated? The Journal of Obstetrics and Gynaecology Research. https://doi.org/10.1111/jog.13667.

37. Jackson, W. F. (2005). Potassium channels in the peripheral microcirculation. Microcirculation, 12(1), 113-127. https://doi.org/ 10.1080/10739680590896072.

38. Burg, E. D., Remillard, C. V., \& Yuan, J. X. (2008). Potassium channels in the regulation of pulmonary artery smooth muscle cell proliferation and apoptosis: Pharmacotherapeutic implications. British Journal of Pharmacology, 153(Suppl 1), S99-S111. https://doi.org/10.1038/sj.bjp.0707635.

39. Perusquia, M., \& Villalon, C. M. (1999). Possible role of $\mathrm{Ca}^{2+}$ channels in the vasodilating effect of 5-beta-dihydrotestosterone in rat aorta. European Journal of Pharmacology, 371(2-3), 169178. https://doi.org/10.1038/sj.bjp.0707635.

40. Cairrao, E., Santos-Silva, A. J., \& Verde, I. (2010). PKG is involved in testosterone-induced vasorelaxation of human umbilical artery. European Journal of Pharmacology, 640, 94-101. https:// doi.org/10.1016/j.ejphar.2010.04.025.

41. Er, F., Michels, G., Brandt, M. C., Khan, I., Haase, H., Eicks, M., et al. (2007). Impact of testosterone on cardiac L-type calcium channels and $\mathrm{Ca}^{2+}$ sparks: Acute actions antagonize chronic effects. Cell Calcium, 41, 467-477. https://doi.org/10.1016/j.ceca.2006.09.003.

42. Harada, N. (2018). Role of androgens in energy metabolism affecting on body composition, metabolic syndrome, type 2 diabetes, cardiovascular disease, and longevity: Lessons from a metaanalysis and rodent studies. Bioscience, Biotechnology, and Biochemistry, 82(10), 1667-1682. https://doi.org/10.1080/ 09168451.2018 .1490172$.

43. English, K. M., Mandour, O., Steeds, R. P., Diver, M. J., Jones, T. H., \& Channer, K. S. (2000). Men with coronary artery disease have lower levels of androgens than men with normal coronary angiograms. European Heart Journal, 21(11), 890-894. https:// doi.org/10.1053/euhj.1999.1873.
44. Kelly, D. M., \& Jones, T. H. (2013). Testosterone: A vascular hormone in health and disease. The Journal of Endocrinology, 217(3), R47-R71. https://doi.org/10.1530/JOE-12-0582.

45. Chrysant, S. G. (2018). Controversies regarding the cardiovascular effects of testosterone replacement therapy in older men. Drugs Today (Barc), 54(1), 25-34. https://doi.org/10.1358/dot.2018.54. 1.2737935

46. Chrysant, S. G., \& Chrysant, G. S. (2018). Cardiovascular benefits and risks of testosterone replacement therapy in older men with low testosterone. Hospital Practice (1995), 46(2), 47-55. https:// doi.org/10.1080/21548331.2018.1445405.

47. Gagliano-Juca, T., \& Basaria, S. (2019). Testosterone replacement therapy and cardiovascular risk. Nature Reviews. Cardiology, 16(9), 555-574. https://doi.org/10.1038/s41569-019-0211-4.

48. Pantalone, K. M., George, J., Ji, X., Kattan, M. W., Milinovich, A., Bauman, J. M., et al. (2019). Testosterone replacement therapy and the risk of adverse cardiovascular outcomes and mortality. Basic and Clinical Andrology, 29, 5. https://doi.org/10.1186/ s12610-019-0085-7.

49. Alberti, K. G., Eckel, R. H., Grundy, S. M., Zimmet, P. Z., Cleeman, J. I., Donato, K. A., et al. (2009). Harmonizing the metabolic syndrome: a joint interim statement of the International Diabetes Federation Task Force on Epidemiology and Prevention; National Heart, Lung, and Blood Institute; American Heart Association; World Heart Federation; International Atherosclerosis Society; and International Association for the Study of Obesity. Circulation, 120(16), 1640-1645. https://doi.org/10.1161/CIRCULATIONAHA.109. 192644.

50. Armani, A., Berry, A., Cirulli, F., \& Caprio, M. (2017). Molecular mechanisms underlying metabolic syndrome: The expanding role of the adipocyte. The FASEB Journal, 31(10), 4240-4255. https:// doi.org/10.1096/fj.201601125RRR.

51. Saklayen, M. G. (2018). The global epidemic of the metabolic syndrome. Current Hypertension Reports, 20(2), 12. https://doi. org/10.1007/s11906-018-0812-z.

52. Yaribeygi, H., Farrokhi, F. R., Butler, A. E., \& Sahebkar, A. (2019). Insulin resistance: Review of the underlying molecular mechanisms. Journal of Cellular Physiology, 234(6), 81528161. https://doi.org/10.1002/jcp.27603.

53. Corona, G., Monami, M., Rastrelli, G., Aversa, A., Tishova, Y., Saad, F., et al. (2011). Testosterone and metabolic syndrome: A meta-analysis study. The Journal of Sexual Medicine, 8(1), 272283. https://doi.org/10.1111/j.1743-6109.2010.01991.x.

54. Corona, G., Rastrelli, G., \& Maggi, M. (2013). Diagnosis and treatment of late-onset hypogonadism: Systematic review and meta-analysis of TRT outcomes. Best Practice \& Research. Clinical Endocrinology \& Metabolism, 27(4), 557-579. https:// doi.org/10.1016/j.beem.2013.05.002.

55. Brand, J. S., van der Tweel, I., Grobbee, D. E., Emmelot-Vonk, M. H., \& van der Schouw, Y. T. (2011). Testosterone, sex hormonebinding globulin and the metabolic syndrome: A systematic review and meta-analysis of observational studies. International Journal of Epidemiology, 40(1), 189-207. https://doi.org/10. 1093/ije/dyq158.

56. Brand, J. S., Rovers, M. M., Yeap, B. B., Schneider, H. J., Tuomainen, T. P., Haring, R., et al. (2014). Testosterone, sex hormone-binding globulin and the metabolic syndrome in men: An individual participant data meta-analysis of observational studies. PLoS One, 9(7), e100409. https://doi.org/10.1371/ journal.pone.0100409.

57. Corona, G., Monami, M., Rastrelli, G., Aversa, A., Sforza, A., Lenzi, A., et al. (2011). Type 2 diabetes mellitus and testosterone: A meta-analysis study. International Journal of Andrology, 34(6 Pt 1), 528-540. https://doi.org/10.1111/j.1365-2605.2010.01117. $\mathrm{x}$ 
58. Ding, E. L., Song, Y., Malik, V. S., \& Liu, S. (2006). Sex differences of endogenous sex hormones and risk of type 2 diabetes: A systematic review and meta-analysis. JAMA, 295(11), 1288-1299. https://doi.org/10.1001/jama.295.11.1288.

59. Rao, P. M., Kelly, D. M., \& Jones, T. H. (2013). Testosterone and insulin resistance in the metabolic syndrome and T2DM in men. Nature Reviews. Endocrinology, 9(8), 479-493. https://doi.org/10. 1038/nrendo.2013.122.

60. Wu, F. C., Tajar, A., Beynon, J. M., Pye, S. R., Silman, A. J., Finn, J. D., et al. (2010). Identification of late-onset hypogonadism in middle-aged and elderly men. The New England Journal of Medicine, 363(2), 123-135. https://doi.org/10.1056/ NEJMoa0911101.

61. Cai, X., Tian, Y., Wu, T., Cao, C. X., Li, H., \& Wang, K. J. (2014). Metabolic effects of testosterone replacement therapy on hypogonadal men with type 2 diabetes mellitus: A systematic review and meta-analysis of randomized controlled trials. Asian Journal of Andrology, 16(1), 146-152. https://doi.org/10.4103/ 1008-682X.122346.

62. Muka, T., Nano, J., Jaspers, L., Meun, C., Bramer, W. M., Hofman, A., et al. (2017). Associations of steroid sex hormones and sex hormone-binding globulin with the risk of type 2 diabetes in women: A population-based cohort study and meta-analysis. Diabetes, 66(3), 577-586. https://doi.org/10.2337/db16-0473.

63. Grossmann, M., Hoermann, R., Wittert, G., \& Yeap, B. B. (2015). Effects of testosterone treatment on glucose metabolism and symptoms in men with type 2 diabetes and the metabolic syndrome: A systematic review and meta-analysis of randomized controlled clinical trials. Clinical Endocrinology, 83(3), 344351. https://doi.org/10.1111/cen.12664.

64. Fruh, S. M. (2017). Obesity: Risk factors, complications, and strategies for sustainable long-term weight management. Journal of the American Association of Nurse Practitioners, 29(S1), S3S14. https://doi.org/10.1002/2327-6924.12510.

65. Benomar, Y., \& Taouis, M. (2019). Molecular mechanisms underlying obesity-induced hypothalamic inflammation and insulin resistance: Pivotal role of resistin/TLR4 pathways. Front Endocrinol (Lausanne), 10, 140. https://doi.org/10.3389/fendo. 2019.00140.

66. Traish, A. M., Guay, A., Feeley, R., \& Saad, F. (2009). The dark side of testosterone deficiency: I. Metabolic syndrome and erectile dysfunction. Journal of Andrology, 30(1), 10-22. https://doi.org/ 10.2164/jandrol.108.005215.

67. Bekaert, M., Van Nieuwenhove, Y., Calders, P., Cuvelier, C. A., Batens, A. H., Kaufman, J. M., et al. (2015). Determinants of testosterone levels in human male obesity. Endocrine, 50(1), 202-211. https://doi.org/10.1007/s12020-015-0563-4.

68. Kovac, J. R., Pastuszak, A. W., Lamb, D. J., \& Lipshultz, L. I. (2014). Testosterone supplementation therapy in the treatment of patients with metabolic syndrome. Postgraduate Medicine, 126(7), 149-156. https://doi.org/10.3810/pgm.2014.11.2843.

69. Bianchi, V. E., \& Locatelli, V. (2018). Testosterone a key factor in gender related metabolic syndrome. Obesity Reviews, 19(4), 557575. https://doi.org/10.1111/obr.12633.

70. Kelly, D. M., \& Jones, T. H. (2015). Testosterone and obesity. Obesity Reviews, 16(7), 581-606. https://doi.org/10.1111/obr. 12282.

71. Chen, R. Y., Wittert, G. A., \& Andrews, G. R. (2006). Relative androgen deficiency in relation to obesity and metabolic status in older men. Diabetes, Obesity \& Metabolism, 8(4), 429-435. https://doi.org/10.1111/j.1463-1326.2005.00532.x.

72. Derby, C. A., Zilber, S., Brambilla, D., Morales, K. H., \& McKinlay, J. B. (2006). Body mass index, waist circumference and waist to hip ratio and change in sex steroid hormones: The Massachusetts male ageing study. Clinical Endocrinology, 65(1), 125-131. https://doi.org/10.1111/j.1365-2265.2006.02560.x.
73. Kaukua, J., Pekkarinen, T., Sane, T., \& Mustajoki, P. (2003). Sex hormones and sexual function in obese men losing weight. Obesity Research, 11(6), 689-694. https://doi.org/10.1038/oby. 2003.98.

74. Niskanen, L., Laaksonen, D. E., Punnonen, K., Mustajoki, P., Kaukua, J., \& Rissanen, A. (2004). Changes in sex hormonebinding globulin and testosterone during weight loss and weight maintenance in abdominally obese men with the metabolic syndrome. Diabetes, Obesity \& Metabolism, 6(3), 208-215. https:// doi.org/10.1111/j.1462-8902.2004.00335.x.

75. Camacho, E. M., Huhtaniemi, I. T., O'Neill, T. W., Finn, J. D., Pye, S. R., Lee, D. M., et al. (2013). Age-associated changes in hypothalamic-pituitary-testicular function in middle-aged and older men are modified by weight change and lifestyle factors: Longitudinal results from the European male ageing study. European Journal of Endocrinology, 168(3), 445-455. https:// doi.org/10.1530/EJE-12-0890.

76. Cunningham, G. R. (2015). Testosterone and metabolic syndrome. Asian Journal of Andrology, 17(2), 192-196. https://doi.org/10. 4103/1008-682X.148068.

77. Zhao, J., Zhai, L., Liu, Z., Wu, S., \& Xu, L. (2014). Leptin level and oxidative stress contribute to obesity-induced low testosterone in murine testicular tissue. Oxidative Medicine and Cellular Longevity, 2014, 190945. https://doi.org/10.1155/2014/190945.

78. Isidori, A. M., Caprio, M., Strollo, F., Moretti, C., Frajese, G., Isidori, A., et al. (1999). Leptin and androgens in male obesity: Evidence for leptin contribution to reduced androgen levels. The Journal of Clinical Endocrinology and Metabolism, 84(10), 3673-3680. https://doi.org/10.1210/jcem.84.10.6082.

79. Yi, X., Gao, H., Chen, D., Tang, D., Huang, W., Li, T., et al. (2017). Effects of obesity and exercise on testicular leptin signal transduction and testosterone biosynthesis in male mice. American Journal of Physiology. Regulatory, Integrative and Comparative Physiology, 312(4), R501-R510. https://doi.org/10.1152/ajpregu. 00405.2016.

80. Pitteloud, N., Hardin, M., Dwyer, A. A., Valassi, E., Yialamas, M., Elahi, D., et al. (2005). Increasing insulin resistance is associated with a decrease in Leydig cell testosterone secretion in men. The Journal of Clinical Endocrinology and Metabolism, 90(5), 26362641. https://doi.org/10.1210/jc.2004-2190.

81. Fink, J., Matsumoto, M., \& Tamura, Y. (2018). Potential application of testosterone replacement therapy as treatment for obesity and type 2 diabetes in men. Steroids, 138, 161-166. https://doi. org/10.1016/j.steroids.2018.08.002.

82. Traish, A. M., \& Zitzmann, M. (2015). The complex and multifactorial relationship between testosterone deficiency (TD), obesity and vascular disease. Reviews in Endocrine \& Metabolic Disorders, 16(3), 249-268. https://doi.org/10.1007/s11154-0159323-2.

83. Corona, G., Mannucci, E., Forti, G., \& Maggi, M. (2009). Hypogonadism, ED, metabolic syndrome and obesity: A pathological link supporting cardiovascular diseases. International Journal of Andrology, 32(6), 587-598. https://doi.org/10.1111/j. 1365-2605.2008.00951.x.

84. Traish, A. M., Feeley, R. J., \& Guay, A. (2009). Mechanisms of obesity and related pathologies: Androgen deficiency and endothelial dysfunction may be the link between obesity and erectile dysfunction. The FEBS Journal, 276(20), 5755-5767. https://doi. org/10.1111/j.1742-4658.2009.07305.x.

85. Libby, P., Buring, J. E., Badimon, L., Hansson, G. K., Deanfield, J., Bittencourt, M. S., et al. (2019). Atherosclerosis. Nature Reviews. Disease Primers, 5(1), 56. https://doi.org/10.1038/ s41572-019-0106-z.

86. Nezu, T., Hosomi, N., Aoki, S., \& Matsumoto, M. (2016). Carotid intima-media thickness for atherosclerosis. Journal of 
Atherosclerosis and Thrombosis, 23(1), 18-31. https://doi.org/10. 5551/jat.31989.

87. van den Beld, A. W., Bots, M. L., Janssen, J. A., Pols, H. A., Lamberts, S. W., \& Grobbee, D. E. (2003). Endogenous hormones and carotid atherosclerosis in elderly men. American Journal of Epidemiology, 157(1), 25-31. https://doi.org/10.1093/aje/kwf160.

88. Fukui, M., Kitagawa, Y., Nakamura, N., Kadono, M., Mogami, S., Hirata, C., et al. (2003). Association between serum testosterone concentration and carotid atherosclerosis in men with type 2 diabetes. Diabetes Care, 26(6), 1869-1873. https://doi.org/10.2337/ diacare.26.6.1869.

89. Svartberg, J., von Muhlen, D., Mathiesen, E., Joakimsen, O., Bonaa, K. H., \& Stensland-Bugge, E. (2006). Low testosterone levels are associated with carotid atherosclerosis in men. Journal of Internal Medicine, 259(6), 576-582. https://doi.org/10.1111/j. 1365-2796.2006.01637.x.

90. De Pergola, G., Pannacciulli, N., Ciccone, M., Tartagni, M., Rizzon, P., \& Giorgino, R. (2003). Free testosterone plasma levels are negatively associated with the intima-media thickness of the common carotid artery in overweight and obese glucose-tolerant young adult men. International Journal of Obesity and Related Metabolic Disorders, 27(7), 803-807. https://doi.org/10.1038/sj. ijo.0802292.

91. Muller, M., van den Beld, A. W., Bots, M. L., Grobbee, D. E., Lamberts, S. W., \& van der Schouw, Y. T. (2004). Endogenous sex hormones and progression of carotid atherosclerosis in elderly men. Circulation, 109(17), 2074-2079. https://doi.org/10.1161/ 01.CIR.0000125854.51637.06.

92. Makinen, J., Jarvisalo, M. J., Pollanen, P., Perheentupa, A., Irjala, K., Koskenvuo, M., et al. (2005). Increased carotid atherosclerosis in andropausal middle-aged men. Journal of the American College of Cardiology, 45(10), 1603-1608. https://doi.org/10. 1016/j.jacc.2005.01.052.

93. Soisson, V., Brailly-Tabard, S., Empana, J. P., Feart, C., Ryan, J., Bertrand, M., et al. (2012). Low plasma testosterone and elevated carotid intima-media thickness: Importance of low-grade inflammation in elderly men. Atherosclerosis, 223(1), 244-249. https:// doi.org/10.1016/j.atherosclerosis.2012.05.009.

94. Farias, J. M., Tinetti, M., Khoury, M., \& Umpierrez, G. E. (2014). Low testosterone concentration and atherosclerotic disease markers in male patients with type 2 diabetes. The Journal of Clinical Endocrinology and Metabolism, 99(12), 4698-4703. https://doi.org/10.1210/jc.2014-2585.

95. Lee, W. C., Kim, M. T., Ko, K. T., Lee, W. K., Kim, S. Y., Kim, H. Y., et al. (2014). Relationship between serum testosterone and cardiovascular disease risk determined using the Framingham risk score in male patients with sexual dysfunction. The World Journal of Men's Health, 32(3), 139-144. https://doi.org/10.5534/wjmh. 2014.32.3.139.

96. Wilson, P. W., D’Agostino, R. B., Levy, D., Belanger, A. M., Silbershatz, H., \& Kannel, W. B. (1998). Prediction of coronary heart disease using risk factor categories. Circulation, 97(18), 1837-1847. https://doi.org/10.1161/01.CIR.97.18.1837.

97. Mahmood, S. S., Levy, D., Vasan, R. S., \& Wang, T. J. (2014). The Framingham heart study and the epidemiology of cardiovascular disease: A historical perspective. Lancet, 383(9921), 999-1008. https://doi.org/10.1016/S0140-6736(13)61752-3.

98. Lee, J. M., Colangelo, L. A., Schwartz, J. E., Yano, Y., Siscovick, D. S., Seeman, T., et al. (2016). Associations of cortisol/ testosterone and cortisol/sex hormone-binding globulin ratios with atherosclerosis in middle-age women. Atherosclerosis, 248, 203209. https://doi.org/10.1016/j.atherosclerosis.2016.03.028.

99. Helkin, A., Stein, J. J., Lin, S., Siddiqui, S., Maier, K. G., \& Gahtan, V. (2016). Dyslipidemia part 1-Review of lipid metabolism and vascular cell physiology. Vascular and Endovascular
Surgery, 50(2), 107-118. https://doi.org/10.1177/ 1538574416628654

100. Stein, R., Ferrari, F., \& Scolari, F. (2019). Genetics, dyslipidemia, and cardiovascular disease: New insights. Current Cardiology Reports, 21(8), 68. https://doi.org/10.1007/s11886-019-1161-5.

101. Shabsigh, R., Katz, M., Yan, G., \& Makhsida, N. (2005). Cardiovascular issues in hypogonadism and testosterone therapy. The American Journal of Cardiology, 96(12B), 67M-72M. https://doi.org/10.1016/j.amjcard.2005.10.009.

102. Haffner, S. M., Mykkanen, L., Valdez, R. A., \& Katz, M. S. (1993). Relationship of sex hormones to lipids and lipoproteins in nondiabetic men. The Journal of Clinical Endocrinology and Metabolism, 77(6), 1610-1615. https://doi.org/10.1210/jcem.77. 6.8263149

103. Agledahl, I., Skjaerpe, P. A., Hansen, J. B., \& Svartberg, J. (2008). Low serum testosterone in men is inversely associated with nonfasting serum triglycerides: The Tromso study. Nutrition, Metabolism, and Cardiovascular Diseases, 18(4), 256-262. https://doi.org/10.1016/j.numecd.2007.01.014.

104. Makinen, J. I., Perheentupa, A., Irjala, K., Pollanen, P., Makinen, J., Huhtaniemi, I., et al. (2008). Endogenous testosterone and serum lipids in middle-aged men. Atherosclerosis, 197(2), 688-693. https://doi.org/10.1016/j.atherosclerosis.2007.05.009.

105. Khaw, K. T., \& Barrett-Connor, E. (1991). Endogenous sex hormones, high density lipoprotein cholesterol, and other lipoprotein fractions in men. Arteriosclerosis and Thrombosis, 11(3), 489494. https://doi.org/10.1161/01.ATV.11.3.489.

106. Vaidya, D., Dobs, A., Gapstur, S. M., Golden, S. H., Hankinson, A., Liu, K., et al. (2008). The association of endogenous sex hormones with lipoprotein subfraction profile in the multi-ethnic study of atherosclerosis. Metabolism, 57(6), 782-790. https://doi. org/10.1016/j.metabol.2008.01.019.

107. Monroe, A. K., \& Dobs, A. S. (2013). The effect of androgens on lipids. Current Opinion in Endocrinology, Diabetes, and Obesity, 20(2), 132-139. https://doi.org/10.1097/MED. 0b013e32835edb71.

108. Thompson, P. D., Cullinane, E. M., Sady, S. P., Chenevert, C., Saritelli, A. L., Sady, M. A., et al. (1989). Contrasting effects of testosterone and stanozolol on serum lipoprotein levels. JAMA, 261(8), 1165-1168. https://doi.org/10.1001/jama.1989. 03420080085036 .

109. Bagatell, C. J., Heiman, J. R., Matsumoto, A. M., Rivier, J. E., \& Bremner, W. J. (1994). Metabolic and behavioral effects of highdose, exogenous testosterone in healthy men. The Journal of Clinical Endocrinology and Metabolism, 79(2), 561-567. https:// doi.org/10.1210/jcem.79.2.8045977.

110. Kalinchenko, S. Y., Tishova, Y. A., Mskhalaya, G. J., Gooren, L. J., Giltay, E. J., \& Saad, F. (2010). Effects of testosterone supplementation on markers of the metabolic syndrome and inflammation in hypogonadal men with the metabolic syndrome: The double-blinded placebo-controlled Moscow study. Clinical Endocrinology, 73(5), 602-612. https://doi.org/10.1111/j.13652265.2010.03845.x.

111. Traish, A. M., \& Kypreos, K. E. (2011). Testosterone and cardiovascular disease: An old idea with modern clinical implications. Atherosclerosis, 214(2), 244-248. https://doi.org/10.1016/j. atherosclerosis.2010.08.078.

112. Traish, A. M., Abdou, R., \& Kypreos, K. E. (2009). Androgen deficiency and atherosclerosis: The lipid link. Vascular Pharmacology, 51(5-6), 303-313. https://doi.org/10.1016/j.vph. 2009.09.003.

113. Lifton, R. P., Gharavi, A. G., \& Geller, D. S. (2001). Molecular mechanisms of human hypertension. Cell, 104(4), 545-556. https://doi.org/10.1016/s0092-8674(01)00241-0.

114. Zitzmann, M., \& Nieschlag, E. (2007). Androgen receptor gene CAG repeat length and body mass index modulate the safety of 
long-term intramuscular testosterone undecanoate therapy in hypogonadal men. The Journal of Clinical Endocrinology and Metabolism, 92(10), 3844-3853. https://doi.org/10.1210/jc.20070620.

115. Traish, A. M., Miner, M. M., Morgentaler, A., \& Zitzmann, M. (2011). Testosterone deficiency. The American Journal of Medicine, 124(7), 578-587. https://doi.org/10.1016/j.amjmed. 2010.12.027.

116. Troisi, R., Potischman, N., Roberts, J. M., Ness, R., Crombleholme, W., Lykins, D., et al. (2003). Maternal serum oestrogen and androgen concentrations in preeclamptic and uncomplicated pregnancies. International Journal of Epidemiology, 32(3), 455-460. https://doi.org/10.1093/ije/dyg094.

117. Sathishkumar, K., Elkins, R., Yallampalli, U., Balakrishnan, M., \& Yallampalli, C. (2011). Fetal programming of adult hypertension in female rat offspring exposed to androgens in utero. Early Human Development, 87(6), 407-414. https://doi.org/10.1016/j. earlhumdev.2011.03.001.

118. Chinnathambi, V., Blesson, C. S., Vincent, K. L., Saade, G. R., Hankins, G. D., Yallampalli, C., et al. (2014). Elevated testosterone levels during rat pregnancy cause hypersensitivity to angiotensin II and attenuation of endothelium-dependent vasodilation in uterine arteries. Hypertension, 64(2), 405-414. https://doi.org/10. 1161/HYPERTENSIONAHA.114.03283.

119. Perez-Sepulveda, A., Monteiro, L. J., Dobierzewska, A., EspanaPerrot, P. P., Venegas-Araneda, P., Guzman-Rojas, A. M., et al. (2015). Placental aromatase is deficient in placental ischemia and preeclampsia. PLoS One, 10(10), e0139682. https://doi.org/10. 1371/journal.pone.0139682.

120. McClamrock, H. D., \& Adashi, E. Y. (1992). Gestational hyperandrogenism. Fertility and Sterility, 57(2), 257-274. https://doi.org/10.1016/S0015-0282(16)54828-6.

121. Bammann, B. L., Coulam, C. B., \& Jiang, N. S. (1980). Total and free testosterone during pregnancy. American Journal of Obstetrics and Gynecology, 137(3), 293-298. https://doi.org/10. 1016/0002-9378(80)90912-6.

122. Honda, H., Unemoto, T., \& Kogo, H. (1999). Different mechanisms for testosterone-induced relaxation of aorta between normotensive and spontaneously hypertensive rats. Hypertension, 34(6), 1232-1236. https://doi.org/10.1161/01.HYP.34.6.1232.

123. Perusquia, M., Herrera, N., Ferrer, M., \& Stallone, J. N. (2017). Antihypertensive effects of androgens in conscious, spontaneously hypertensive rats. The Journal of Steroid Biochemistry and Molecular Biology, 167, 106-114. https://doi.org/10.1016/j. jsbmb.2016.11.016.

124. Isidoro, L., Ferrer, M., \& Perusquia, M. (2018). Vasoactive androgens: Vasorelaxing effects and their potential regulation of blood pressure. Endocrine Research, 43(3), 166-175. https://doi.org/10. 1080/07435800.2018.1448868.

125. Perusquia, M., Hanson, A. E., Meza, C. M., Kubli, C., Herrera, N., $\&$ Stallone, J. N. (2018). Antihypertensive responses of vasoactive androgens in an in vivo experimental model of preeclampsia. The Journal of Steroid Biochemistry and Molecular Biology, 178, 6572. https://doi.org/10.1016/j.jsbmb.2017.11.001.

126. Jones, T. H., \& Kelly, D. M. (2018). Randomized controlled trials mechanistic studies of testosterone and the cardiovascular system. Asian Journal of Andrology, 20(2), 120-130. https://doi.org/10. 4103/aja.aja_6_18.

127. Tirabassi, G., Gioia, A., Giovannini, L., Boscaro, M., Corona, G., Carpi, A., et al. (2013). Testosterone and cardiovascular risk. Internal and Emergency Medicine, 8(Suppl 1), S65-S69. https:// doi.org/10.1007/s11739-013-0914-1.
128. Phillips, G. B., Castelli, W. P., Abbott, R. D., \& McNamara, P. M. (1983). Association of hyperestrogenemia and coronary heart disease in men in the Framingham cohort. The American Journal of Medicine, 74(5), 863-869. https://doi.org/10.1016/0002-9343(83) 91078-1.

129. Zhao, S. P., \& Li, X. P. (1998). The association of low plasma testosterone level with coronary artery disease in Chinese men. International Journal of Cardiology, 63(2), 161-164. https://doi. org/10.1016/s0167-5273(97)00295-7.

130. Chan, Y. X., Knuiman, M. W., Hung, J., Divitini, M. L., Handelsman, D. J., Beilby, J. P., et al. (2015). Testosterone, dihydrotestosterone and estradiol are differentially associated with carotid intima-media thickness and the presence of carotid plaque in men with and without coronary artery disease. Endocrine Journal, 62(9), 777-786. https://doi.org/10.1507/endocrj.EJ15-0196.

131. Debing, E., Peeters, E., Duquet, W., Poppe, K., Velkeniers, B., \& Van Den Brande, P. (2008). Men with atherosclerotic stenosis of the carotid artery have lower testosterone levels compared with controls. International Angiology, 27(2), 135-141.

132. Vikan, T., Johnsen, S. H., Schirmer, H., Njolstad, I., \& Svartberg, J. (2009). Endogenous testosterone and the prospective association with carotid atherosclerosis in men: The Tromso study. European Journal of Epidemiology, 24(6), 289-295. https://doi. org/10.1007/s10654-009-9322-2.

133. Yeap, B. B., Alfonso, H., Chubb, S. A., Handelsman, D. J., Hankey, G. J., Golledge, J., et al. (2013). Lower plasma testosterone or dihydrotestosterone, but not estradiol, is associated with symptoms of intermittent claudication in older men. Clinical Endocrinology, 79(5), 725-732. https://doi.org/10.1111/cen. 12208 .

134. Rosano, G. M., Sheiban, I., Massaro, R., Pagnotta, P., Marazzi, G., Vitale, C., et al. (2007). Low testosterone levels are associated with coronary artery disease in male patients with angina. International Journal of Impotence Research, 19(2), 176-182. https://doi.org/10.1038/sj.ijir.3901504.

135. Goodale, T., Sadhu, A., Petak, S., \& Robbins, R. (2017). Testosterone and the heart. Methodist DeBakey Cardiovascular Journal, 13(2), 68-72. https://doi.org/10.14797/mdcj-13-2-68.

136. Corona, G., Rastrelli, G., Vignozzi, L., Mannucci, E., \& Maggi, M. (2011). Testosterone, cardiovascular disease and the metabolic syndrome. Best Practice \& Research. Clinical Endocrinology \& Metabolism, 25(2), 337-353. https://doi.org/10.1016/j.beem. 2010.07.002.

137. Jankowska, E. A., Biel, B., Majda, J., Szklarska, A., Lopuszanska, M., Medras, M., et al. (2006). Anabolic deficiency in men with chronic heart failure: Prevalence and detrimental impact on survival. Circulation, 114(17), 1829-1837. https://doi.org/10.1161/ CIRCULATIONAHA.106.649426.

138. Srinivas-Shankar, U., Roberts, S. A., Connolly, M. J., O'Connell, M. D., Adams, J. E., Oldham, J. A., et al. (2010). Effects of testosterone on muscle strength, physical function, body composition, and quality of life in intermediate-frail and frail elderly men: A randomized, double-blind, placebo-controlled study. The Journal of Clinical Endocrinology and Metabolism, 95(2), 639650. https://doi.org/10.1210/jc.2009-1251.

139. Jeppesen, L. L., Jorgensen, H. S., Nakayama, H., Raaschou, H. O., Olsen, T. S., \& Winther, K. (1996). Decreased serum testosterone in men with acute ischemic stroke. Arteriosclerosis, Thrombosis, and Vascular Biology, 16(6), 749-754. https://doi.org/10.1161/01. atv.16.6.749.

140. Yeap, B. B., Hyde, Z., Almeida, O. P., Norman, P. E., Chubb, S. A., Jamrozik, K., et al. (2009). Lower testosterone levels predict incident stroke and transient ischemic attack in older men. The 
Journal of Clinical Endocrinology and Metabolism, 94(7), 23532359. https://doi.org/10.1210/jc.2008-2416.

141. Yeap, B. B., Hyde, Z., Norman, P. E., Chubb, S. A., \& Golledge, J. (2010). Associations of total testosterone, sex hormone-binding globulin, calculated free testosterone, and luteinizing hormone with prevalence of abdominal aortic aneurysm in older men. The Journal of Clinical Endocrinology and Metabolism, 95(3), 11231130. https://doi.org/10.1210/jc.2009-1696.

142. Magnani, J. W., Moser, C. B., Murabito, J. M., Sullivan, L. M., Wang, N., Ellinor, P. T., et al. (2014). Association of sex hormones, aging, and atrial fibrillation in men: The Framingham heart study. Circulation. Arrhythmia and Electrophysiology, 7(2), 307312. https://doi.org/10.1161/CIRCEP.113.001322.

143. Zeller, T., Schnabel, R. B., Appelbaum, S., Ojeda, F., Berisha, F., Schulte-Steinberg, B., et al. (2018). Low testosterone levels are predictive for incident atrial fibrillation and ischaemic stroke in men, but protective in women - results from the FINRISK study. European Journal of Preventive Cardiology, 25(11), 1133-1139. https://doi.org/10.1177/2047487318778346.

144. Lai, J., Zhou, D., Xia, S., Shang, Y., Want, L., Zheng, L., et al. (2009). Reduced testosterone levels in males with lone atrial fibrillation. Clinical Cardiology, 32(1), 43-46. https://doi.org/10. 1002/clc. 20423.

145. Zhang, Y., Wang, H. M., Wang, Y. Z., Zhang, Y. Y., Jin, X. X., Zhao, Y., et al. (2017). Increment of late sodium currents in the left atrial myocytes and its potential contribution to increased susceptibility of atrial fibrillation in castrated male mice. Heart Rhythm, 14(7), 1073-1080. https://doi.org/10.1016/j.hrthm.2017.01.046.

146. Rosenberg, M. A., Shores, M. M., Matsumoto, A. M., Bǔžková, P., Lange, L. A., Kronmal, R. A., et al. (2018). Serum androgens and risk of atrial fibrillation in older men: The cardiovascular health study. Clinical Cardiology, 41(6), 830-836. https://doi. org/10.1002/clc.22965.

147. Berger, D., Folsom, A. R., Schreiner, P. J., Chen, L. Y., Michos, E. D., O'Neal, W. T., et al. (2019). Plasma total testosterone and risk of incident atrial fibrillation: The atherosclerosis risk in communities (ARIC) study. Maturitas, 125, 5-10. https://doi.org/10.1016/j. maturitas.2019.03.015.

148. O'Neal, W. T., Nazarian, S., Alonso, A., Heckbert, S. R., Vaccarino, V., \& Soliman, E. Z. (2017). Sex hormones and the risk of atrial fibrillation: The multi-ethnic study of atherosclerosis (MESA). Endocrine, 58(1), 91-96. https://doi.org/10.1007/ s12020-017-1385-3.

149. Hackett, G. (2019). Metabolic effects of testosterone therapy in men with type 2 diabetes and metabolic syndrome. Sex Med Rev, 7(3), 476-490. https://doi.org/10.1016/j.sxmr.2018.12.004.

150. Sizar, O., \& Pico, J. (2019). Androgen replacement. In StatPearls. Treasure Island (FL)

151. Snyder, P. J., Bhasin, S., Cunningham, G. R., Matsumoto, A. M., Stephens-Shields, A. J., Cauley, J. A., et al. (2018). Lessons from the testosterone trials. Endocrine Reviews, 39(3), 369-386. https:// doi.org/10.1210/er.2017-00234.

152. Budoff, M. J., Ellenberg, S. S., Lewis, C. E., Mohler 3rd, E. R., Wenger, N. K., Bhasin, S., et al. (2017). Testosterone treatment and coronary artery plaque volume in older men with low testosterone. JAMA, 317(7), 708-716. https://doi.org/10.1001/jama. 2016.21043.

153. Mohler 3rd, E. R., Ellenberg, S. S., Lewis, C. E., Wenger, N. K., Budoff, M. J., Lewis, M. R., et al. (2018). The effect of testosterone on cardiovascular biomarkers in the testosterone trials. The Journal of Clinical Endocrinology and Metabolism, 103(2), 681-688. https://doi.org/10.1210/jc.2017-02243.
154. Keya, S. L., Khanam, N. N., Chowdhury, A. A., Ripon, R., Tasnim, T., \& Sharmin, A. (2019). Relationship between free testosterone and preeclampsia. Mymensingh Medical Journal, 28, 574-581.

155. Kloner, R. A., Carson 3rd, C., Dobs, A., Kopecky, S., \& Mohler 3rd, E. R. (2016). Testosterone and cardiovascular disease. Journal of the American College of Cardiology, 67(5), 545-557. https://doi.org/10.1016/j.jacc.2015.12.005.

156. Baillargeon, J., Urban, R. J., Kuo, Y. F., Ottenbacher, K. J., Raji, M. A., Du, F., et al. (2014). Risk of myocardial infarction in older men receiving testosterone therapy. The Annals of Pharmacotherapy, 48(9), 1138-1144. https://doi.org/10.1177/ 1060028014539918.

157. Dobrzycki, S., Serwatka, W., Nadlewski, S., Korecki, J., Jackowski, R., Paruk, J., et al. (2003). An assessment of correlations between endogenous sex hormone levels and the extensiveness of coronary heart disease and the ejection fraction of the left ventricle in males. The Journal of Medical Investigation, 50, 162-169.

158. Soisson, V., Brailly-Tabard, S., Helmer, C., Rouaud, O., Ancelin, M. L., Zerhouni, C., et al. (2013). A J-shaped association between plasma testosterone and risk of ischemic arterial event in elderly men: The French 3C cohort study. Maturitas, 75(3), 282-288. https://doi.org/10.1016/j.maturitas.2013.04.012.

159. Muraleedharan, V., Marsh, H., Kapoor, D., Channer, K. S., \& Jones, T. H. (2013). Testosterone deficiency is associated with increased risk of mortality and testosterone replacement improves survival in men with type 2 diabetes. European Journal of Endocrinology, 169(6), 725-733. https://doi.org/10.1530/EJE13-0321.

160. Jankowska, E. A., Filippatos, G., Ponikowska, B., BorodulinNadzieja, L., Anker, S. D., Banasiak, W., et al. (2009). Reduction in circulating testosterone relates to exercise capacity in men with chronic heart failure. Journal of Cardiac Failure, 15(5), 442-450. https://doi.org/10.1016/j.cardfail.2008.12.011.

161. Pugh, P. (2003). Acute haemodynamic effects of testosterone in men with chronic heart failure. European Heart Journal, 24(10), 909-915. https://doi.org/10.1016/s0195-668x(03)00083-6.

162. Malkin, C. J., Pugh, P. J., Jones, R. D., Kapoor, D., Channer, K. S., \& Jones, T. H. (2004). The effect of testosterone replacement on endogenous inflammatory cytokines and lipid profiles in hypogonadal men. The Journal of Clinical Endocrinology and Metabolism, 89(7), 3313-3318. https://doi.org/10.1210/jc.2003031069.

163. Deenadayalu, V., Puttabyatappa, Y., Liu, A. T., Stallone, J. N., \& White, R. E. (2012). Testosterone-induced relaxation of coronary arteries: Activation of BKCa channels via the cGMP-dependent protein kinase. American Journal of Physiology. Heart and Circulatory Physiology, 302(1), H115-H123. https://doi.org/10. 1152/ajpheart.00046.2011.

164. Jones, R. D., Pugh, P. J., Jones, T. H., \& Channer, K. S. (2003). The vasodilatory action of testosterone: A potassium-channel opening or a calcium antagonistic action? British Journal of Pharmacology, 138(5), 733-744.

165. Oskui, P. M., French, W. J., Herring, M. J., Mayeda, G. S., Burstein, S., \& Kloner, R. A. (2013). Testosterone and the cardiovascular system: A comprehensive review of the clinical literature. Journal of the American Heart Association, 2(6), e000272. https:// doi.org/10.1161/JAHA.113.000272.

166. Vigen, R., O'Donnell, C. I., Baron, A. E., Grunwald, G. K., Maddox, T. M., Bradley, S. M., et al. (2013). Association of testosterone therapy with mortality, myocardial infarction, and stroke in men with low testosterone levels. JAMA, 310(17), 1829-1836. https://doi.org/10.1001/jama.2013.280386. 
167. Finkle, W. D., Greenland, S., Ridgeway, G. K., Adams, J. L., Frasco, M. A., Cook, M. B., et al. (2014). Increased risk of nonfatal myocardial infarction following testosterone therapy prescription in men. PLoS One, 9(1), e85805. https://doi.org/10. 1371/journal.pone.0085805.

168. Webb, C. M., \& Collins, P. (2017). Role of testosterone in the treatment of cardiovascular disease. European Cardiology, 12(2), 83-87. https://doi.org/10.15420/ecr.2017:21:1.

169. Morgentaler, A., \& Kacker, R. (2014). Andrology: Testosterone and cardiovascular risk-Deciphering the statistics. Nature Reviews. Urology, 11(3), 131-132. https://doi.org/10.1038/ nrurol.2014.24.

170. Sharma, R., Oni, O. A., Gupta, K., Chen, G., Sharma, M., Dawn, B., et al. (2015). Normalization of testosterone level is associated with reduced incidence of myocardial infarction and mortality in men. European Heart Journal, 36(40), 2706-2715. https://doi. org/10.1093/eurheartj/ehv346.

171. Cheetham, T. C., An, J., Jacobsen, S. J., Niu, F., Sidney, S., Quesenberry, C. P., et al. (2017). Association of testosterone replacement with cardiovascular outcomes among men with androgen deficiency. JAMA Internal Medicine, 177(4), 491-499. https://doi.org/10.1001/jamainternmed.2016.9546.

172. Chistiakov, D. A., Myasoedova, V. A., Melnichenko, A. A., Grechko, A. V., \& Orekhov, A. N. (2018). Role of androgens in cardiovascular pathology. Vascular Health and Risk Management, 14, 283-290. https://doi.org/10.2147/VHRM.S173259.

Publisher's Note Springer Nature remains neutral with regard to jurisdictional claims in published maps and institutional affiliations. 